\title{
Constructing uranyl-specific nanofluidic channels for unipolar ionic transport to realize ultra-fast uranium extraction
}

Zeyu Wang, Rongchen Ma, Qinghao Meng, Yajie Yang, Xujiao Ma, Xianghui Ruan, Ye Yuan*, and Guangshan Zhu*

Key Laboratory of Polyoxometalate and Reticular Material Chemistry of Ministry of Education, Northeast Normal University. Changchun 130012, China.

*Email: Yuany101@nenu.edu.cn and Zhugs@nenu.edu.cn 


\section{Supporting Information Text}

\section{Materials and Methods}

1.1. Chemicals: Graphene oxide (GO) was prepared according to the modified Hummer's method. ${ }^{1}$ Tetrakis(triphenylphosphine)palladium(0) (ACS reagent, $\geq$ 98\%), salicylaldoxime (ACS reagent, $\geq 98 \%$ ), 1,8-diazabicclo[5.4.0]under-7-ene (ACS reagent, $\geq 98 \%$ ), diethylbromomalonate (ACS reagent, $\geq 98 \%$ ), 1,4phenylenebisboronic acid (ACS reagent, $\geq 98 \%$ ), and 4,4'-biphenyldiboronic acid (ACS reagent, $\geq 98 \%$ ) were purchased from $3 \mathrm{~A}$ chemical and used as received. Millipore water $(18.2 \mathrm{M} \Omega \cdot \mathrm{cm})$ was used for sample rinsing.

1.2. Measurements: Fourier Transform infrared (FT-IR) spectrum was recorded on a Nicolet Impact 410 using $\mathrm{KBr}$ pellets in the $400-4000 \mathrm{~cm}^{-1}$ region. Raman spectrum was recorded on a Bruker RFS100 Raman Spectrometer. Powder X-ray diffraction was performed on a Smartlab instrument with monochromatic $\mathrm{Cu} \mathrm{K \alpha}$ radiation $(\lambda=1.5406 \AA)$. $N_{2}$ sorption experiment was carried out at liquid nitrogen temperature $(77 \mathrm{~K})$ using a Quanta chrome Autosorb. Thermogravimetric measurement was carried out in an air stream with a METTLER-TOLEDO TGA/DSC $3+$ analyser with a $10{ }^{\circ} \mathrm{C} \mathrm{min}^{-1}$ heating rate. Inductively coupled plasma mass spectrometry (ICP-MS) was performed on a PerkinElmer Optima 3300DV. Scanning electron microscopy (SEM) and energy-dispersive spectroscopy (EDS) data were carried out on a JEOS JSM 6700. Transmission electron microscopy (TEM) was measured on the JEM Grand ARM300F. The Elemental analysis was measured on the Perkin Elmer 2400 Series IICHNS/O Analyzer.

1.3. Synthesis of rGO-Br: As shown in Figure S1, $20 \mathrm{mg} \mathrm{GO}$ powder was dispersed in deionized water $(20 \mathrm{~mL})$, follow by ultrasonication for $1 \mathrm{~h}$ to obtain a $1 \mathrm{mg} \mathrm{mL}^{-1}$ dilute GO dispersion. Then, NBS (268 mg), silver nitrate (170 mg), and acetonitrile $(10 \mathrm{~mL})$ were added. The mixture was heated to $90{ }^{\circ} \mathrm{C}$ for $12 \mathrm{~h}$ under nitrogen atmosphere, and then cooled down to room temperature. The black solution was poured into $100 \mathrm{~mL}$ deionized water, followed by adding sodium thiosulfate (1.5 $\mathrm{g}$ ), and stirred for $2 \mathrm{~h}$ at room temperature. The black power was vacuum filtrated, washed with deionized water and ethanol for several times, and dried under vacuum at $100{ }^{\circ} \mathrm{C}$ to obtain rGO-Br.

1.4. Synthesis of physically mixed sample (MIGPAF-13-PM): Salicylaldoxime $(1 \mathrm{~g})$ and $\mathrm{UO}_{2}\left(\mathrm{NO}_{3}\right)_{2} \cdot 6 \mathrm{H}_{2} \mathrm{O}(1 \mathrm{~g})$ were dissolved in $50 \mathrm{~mL}$ 2-methoxyethanol under stirring at room temperature; the GPAF-13 (50 mg) was added and stirred for 12 $\mathrm{h}$ at room temperature. Finally, the filtered product was washed with aqueous $\mathrm{Na}_{2} \mathrm{CO}_{3}$ solution for several times and dried for further characterization, named as MIGPAF-13-PM.

MIGPAF-13-PM solid was determined to reveal uranium capacity of $135 \mathrm{mg} / \mathrm{g}$ after $60 \mathrm{~min}$ of contact. After three uranyl adsorption-desorption cycles, the capacity of MIGPAF-13-PM reduced to $80 \mathrm{mg} / \mathrm{g}$ after $60 \mathrm{~min}$ contact.

\section{Experiments:}


2.1. Uranyl ion uptake tests: The solution with uranyl ion was prepared by dissolving $\mathrm{UO}_{2}\left(\mathrm{NO}_{3}\right)_{2} \cdot 6 \mathrm{H}_{2} \mathrm{O}$ into real seawater which was collected from Bohai sea (China) with the initial uranyl concentration of $\sim 3.3 \mathrm{ppb}$. The real seawater was vacuum filtered through a $0.2-\mu \mathrm{m}$ filter to remove the large particles and microorganisms before used.

In generally, a total $2.0 \mathrm{~L}$ spiked real seawater was circuited continuously by a peristaltic pump with a flow rate of $80 \mathrm{~mL} / \mathrm{min}$, and the solution volume in the electrosorption tank was kept about $200 \mathrm{~mL}$. A MIGPAFs samples loaded on carbon felt or glass carbon electrode (GCE) by dip-coated method was used as negative electrode, a carbon rod with $0.6 \mathrm{~cm}$ diameter was used as the positive electrode. The uranium concentration was measured by inductively coupled plasma mass spectrometry (ICP-MS). Concrete steps: The MIGPAF carbon felt electrode was tested in real seawater for a period of time; after extraction under bias, the electrode was take out and drying by vacuum oven $\left(100{ }^{\circ} \mathrm{C}\right)$. After that the electrode was put into aqua regia for 12 hours; the collected solution was prediluted by deionized water for machines testing requirement (Thermofisher iCAP $\mathrm{RQ}$, slightly acidic and clear aqueous solution), and filtration for tested; for each test, ca. $5 \mathrm{~mL}$ collected solution were used.

The uranyl sorption capacity $\left(\mathrm{Q}_{\mathrm{e}}\right)$ was calculated using the following equation:

$$
Q_{e}=\left(C_{0}-C_{e}\right) V / m
$$

Where $C_{0}$ and $C_{e}$ are the initially and equilibrium concentration $\left(\mathrm{mg} \mathrm{L}^{-1}\right)$, respectively. $V$ is the volume of initial solution, and $m$ is the dry weight of MIGPAFs used.

The concentration of uranium after the extraction falls in the range of 0.01-0.5 ppb. Inductively coupled plasma massspectrometry (ICP-MS, Thermofisher, iCAP $\mathrm{RQ}$ ) with to detection limit of $0.1 \mathrm{ppt}$ is capable for the fine detection of the $\mathrm{U}$ concentration. After extraction by MIGPAFs under bias, $6 \times 4 \mathrm{~mL}$ of seawater is collected, the concentrations of uranium are direct tested by ICP-MS. Before the testing, the uranium standard solution (998 ppm) is diluted into consistency, and these solutions are testing to draw the standard curve.

2.2. Adsorption isotherms: The adsorption kinetic data can be analyzed according to the pseudo-second-order kinetics, which can be expressed as:

$$
\frac{t}{Q_{t}}=\frac{1}{k_{2} Q_{e}^{2}}+\frac{t}{Q_{e}}
$$

where $t$ is the contact time ( $\mathrm{min}$ ), $Q_{t}$ and $Q_{e}$ are the amount of uranyl ions adsorbed at an arbitrary time $\mathrm{t}$ and at equilibrium $\left(\mathrm{mg} \mathrm{g}^{-1}\right)$, respectively, and $k_{2}$ is the rate constant $\left(\mathrm{g} \mathrm{mg}^{-1} \mathrm{~min}^{-1}\right)$. Plots $t / Q_{t}$ vs. $t$ of the kinetics data are linear. 
The Distribution coefficient of MIGPAFs for uranyl ions was measured using the following equation:

$$
K_{d}=\frac{\left(C_{0}-C_{e}\right)}{C_{e}} \times \frac{V}{m}
$$

where, $K_{d}$ is the distribution coefficient, $C_{0}$ and $C_{e}$ are the initially and equilibrium concentration ( $\mathrm{mg} \mathrm{L}^{-1}$ ), $V$ is the volume of initial solution, and $m$ is the dry weight of MIGPAFs used in solution.

2.3. Ion selectivity test: The selectivity of MIGPAF samples for uranyl species was studied in the presence of different metal ions in seawater. One MIGPAF/carbon felt electrode was tested in a beaker containing a total of $2000 \mathrm{~mL}$ of spiked real

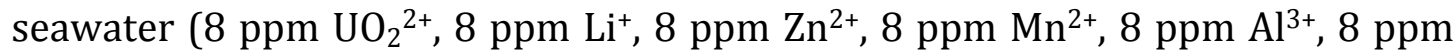

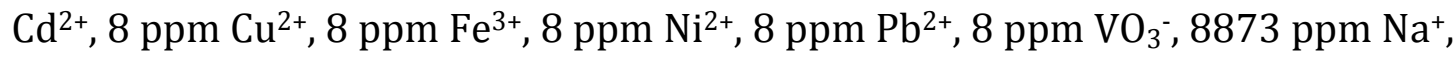
$1039 \mathrm{ppm} \mathrm{Mg}^{2+}, 724 \mathrm{ppm} \mathrm{K}^{+}$, and $401 \mathrm{ppm} \mathrm{Ca}^{2+}$ ), and a total $2.0 \mathrm{~L}$ spiked real seawater was circuited continuously by a peristaltic pump with a flow rate of 80 $\mathrm{mL} / \mathrm{min}$. After extraction, the concentrations of uranium and other metals ions were afforded by ICP-MS. The selectivity coefficient $K_{(\mathrm{U} / \mathrm{M})}$ is used as the criterion of performance evaluation:

$$
K_{(U / M)}=\frac{Q_{U}}{Q_{M}}
$$

Where $Q_{U}$ and $Q_{M}$ are the amount of uranyl ions and metal ions adsorbed at equilibrium $\left(\mathrm{mg} \mathrm{g}^{-1}\right)$, respectively.

2.4. Recycle test: To elute uranyl ion from the MIGPAF@U, a constant oxidizing potential of $+0.7 \mathrm{~V}$ was applied to the MIGPAFs electrode for up to $2 \mathrm{~h}$ in water $(15$ $\mathrm{mL}$ ) at room temperature, with gently stirring. Subsequently, the MIGPAFs electrode was reactivated for $10 \mathrm{~min}$ at $+0.1 \mathrm{~V}$ in a fresh water for the next cycle of testing.

2.5. Electrochemistry test: Electrochemical studies were carried out under ambient conditions with a $\mathrm{CHI} 660 \mathrm{E}$ (CH Instruments Ins.). A three-electrode configuration consisting of the MIGPAFs/carbon felt electrode as the working electrode, $\mathrm{Ag} / \mathrm{AgCl}(3 \mathrm{M} \mathrm{KCl})$ as a reference electrode, and a carbon rod as a counter electrode. The supporting electrolyte were $1 \mathrm{M} \mathrm{KCl}$ solution containing 5 $\mathrm{mM} \mathrm{K}_{4} \mathrm{Fe}(\mathrm{CN})_{6}$ in the deionized water. In the AACE method, the voltage alternates between a negative value and zero with the duration times of $0.5 \mathrm{~ms}$ for $-1.3 \mathrm{~V}$ and $2 \mathrm{~ms}$ for $0 \mathrm{~V}$.

2.6. Preparation of coated electrode: Carbon felt (CeTech, WOS1009) was cut into $4 \mathrm{~cm}^{2}$ square shapes as electrode substrates. MIGPAFs samples, PVDF (mass ratio of 8:2) was suspended into N-Methyl pyrrolidone (NMP) solvent. The solution was stirred to form a uniform slurry. The carbon felt substrate was then 
dip-coated with the slurry and air-dried on a hotplate $\left(70^{\circ} \mathrm{C}\right), c a .2-4 \mathrm{mg}$ MIGPAFs powder was loaded onto the carbon felt. For the long-term flow experiment, sandwich type panel structure (carbon felt-MIGPAFs-carbon felt) was used as the electrode.

2.7. Structural analysis: As depicted in scanning electron microscopy (SEM) images (Figure S10), all graphene-based PAFs solids show a bird's nest-like structure. High-resolution transmission electron microscopy (HRTEM) indicates that the GPAFs and MIGPAFs are short of long-range ordered structures (Figure S11). The uniform dispersion of $\mathrm{N}$ atoms in the energy-dispersive spectrometry (EDS) mapping suggests an evenly distributed salicylaldoxime group within the MIGPAFs solids (Figure S24). Based on the CHN elemental analysis (Table S1), there were sharp increases in N contents (from $3.6 \mathrm{wt} \%$ for MIGPAF-12 to $0.1 \mathrm{wt} \%$ for GPAF-12 and from $4.2 \mathrm{wt} \%$ for MIGPAF-13 to $0.1 \mathrm{wt} \%$ for GPAF-13, respectively), suggesting the successful decoration of salicylaldoxime groups on GPAFs skeletons. The amounts of uranyl-specific bis-salicylaldoxime entities in MIGPAFs were calculated according to the nitrogen elemental analysis (Table S1). Correspondingly, 1.31 and $1.52 \mathrm{mmol} \mathrm{g}^{-1}$ of the bis-salicylaldoxime entity were determined to be decorated on MIGPAF-12 and MIGPAF-13, respectively. Thermogravimetric analysis (TGA) under air conditions indicated that all PAF samples showed considerable thermal stability up to $300^{\circ} \mathrm{C}$ (Figure S15).

\subsection{Uranyl ion enrichment using alternating current electrochemical (AACE)} method: In this work, we choose nickel sheet and nickel foam with a square shape $\left(2 \times 2 \mathrm{~cm}^{2}\right)$ as a negative electrode, and carbon felt $\left(2 \times 2 \mathrm{~cm}^{2}\right)$ as a positive electrode to examine the uranyl-enrichment capability. Under the alternating current electrochemical (AACE) method, the voltage alternates between $-1.3 \mathrm{~V}$ and $0 \mathrm{~V}$ were used with the duration times of $0.5 \mathrm{~ms}$ for $-1.3 \mathrm{~V}$ and $2 \mathrm{~ms}$ for $0 \mathrm{~V}$. The AACE method avoids the evolution of hydrogen gas (HER reaction), to prevent affect the enrichment of uranyl ions.

The cyclic voltammetry (CV) was first tested in the real seawater spiked with $\sim 8 \mathrm{ppm}$ uranyl ion via a two-electrode system. There is no obvious reduction/oxidation peak observed from -1.3 to $0.0 \mathrm{~V}$ in the scanning cycle confirming that no variation in uranyl species (Figure S2).

The uranyl-enrichment ability was measured in a spiked real seawater with the initial concentration of $3.3 \times 10^{-3}, 8,100$, and 1000 ppm uranyl ions, trace uranium was obtained by micro-injector $(10 \mu \mathrm{L})$ around and interior the conductive electrode (nickel sheet and nickel foam), respectively. As illustrated in Figures S3 and S4, the condensed concentrations within the nickel foam are $\sim 1850$ for $\sim 1000$ ppm (equilibrium time of $0.5 \mathrm{~h}$ ), which is much higher than those obtained around the nickel foam and nickel sheet. The values are $\sim 200$ for $\sim 100 \mathrm{ppm}$ (equilibrium time of $1 \mathrm{~h}$ ), $\sim 35$ for $\sim 8 \mathrm{ppm}$ (equilibrium time of $5 \mathrm{~h}$ ), respectively. Due to the overlapping EDLs in pore conductive material (nickel foam), the porous material could enrich more ions to balance the surface charge and maintain the charge 
neutrality. Meanwhile, the final uranyl concentration reaches a value $\sim 40.0 \times 10^{-3}$ ppm from $\sim 3.3 \times 10^{-3} \mathrm{ppm}$ of an initial concentration in $48 \mathrm{~h}$.

2.9. Electrochemical performance: The electrochemical performance of graphene-based PAF materials was measured in a three-electrode cell, where a 1 $\mathrm{M} \mathrm{KCl}$ aqueous solution containing $10 \mathrm{mM} \mathrm{K}_{4} \mathrm{Fe}(\mathrm{CN})_{6}$ was used as the supporting electrolyte. ${ }^{2,3}$ As expected, all MIGPAF samples displayed a low peak-to-peak linewidth (0.14 V for MIGPAF-13 and $0.12 \mathrm{~V}$ for MIGPAF-12) from the reversible cyclic voltammograms (CV) tests, which corresponded to the fast electron transfer kinetics (Figure S17). Electrochemical impedance spectroscopy (EIS) analyses were performed for the MIGPAFs to further reveal the electrotransfer characteristics (Figure S18). As depicted by the Nyquist plots in the EIS spectra, the MIGPAF powders attached on the glassy carbon electrode (GCE) exhibited a similar Randles equivalent circuit response, with a semicircle in the high frequency region and a linear line in the low frequency region. ${ }^{4}$ All MIGPAFs samples revealed a small charge transfer resistance $\left(\mathrm{R}_{\mathrm{ct}}\right)$, which confirmed the low contact resistance during the electron transport at the MIGPAFs solid/electrode interface. Regarding the linear lines in the low frequency region, the slope of the line reflected the diffusive resistivity of the ions. ${ }^{5}$ The steeper line of MIGPAF-13 than MIGPAF-12 proved its lower diffusive resistivity and quicker migration of ions. ${ }^{5}$ The double-layer capacitance $\left(\mathrm{C}_{\mathrm{dl}}\right)$ was tested to estimate the electrochemically active surface areas (ECSAs) of the MIGPAF samples (Figure S19). ${ }^{2}$ The ESCA values for MIGPAF-12 and MIGPAF-13 are 1.4 and 2.0 times larger than that of GO, respectively. These results demonstrated that the MIGPAF frameworks with phenyl unit-pillared graphene laminates effectively increased the accessible surface area, leading to enhanced electrochemical performance. ${ }^{6}$ Both EIS and $\mathrm{C}_{\mathrm{dl}}$ analysis proved that the biphenyl-pillar inserted sample (MIGPAF-13) fit better for uranyl ion capture under electrochemical processes. 


\section{Supporting Information Figures}

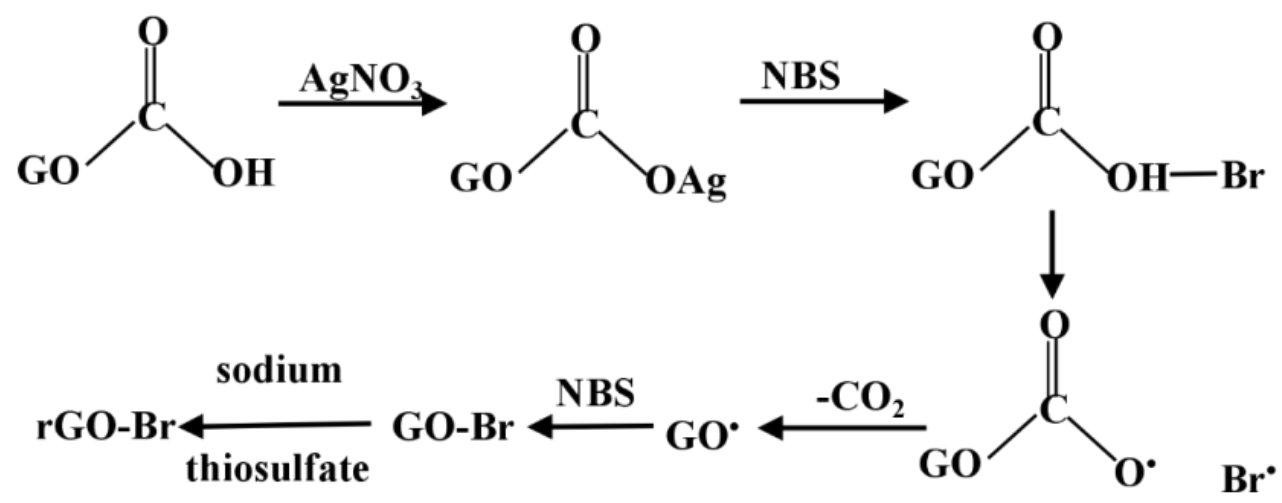

Figure S1. Synthesis of rGO-Br.

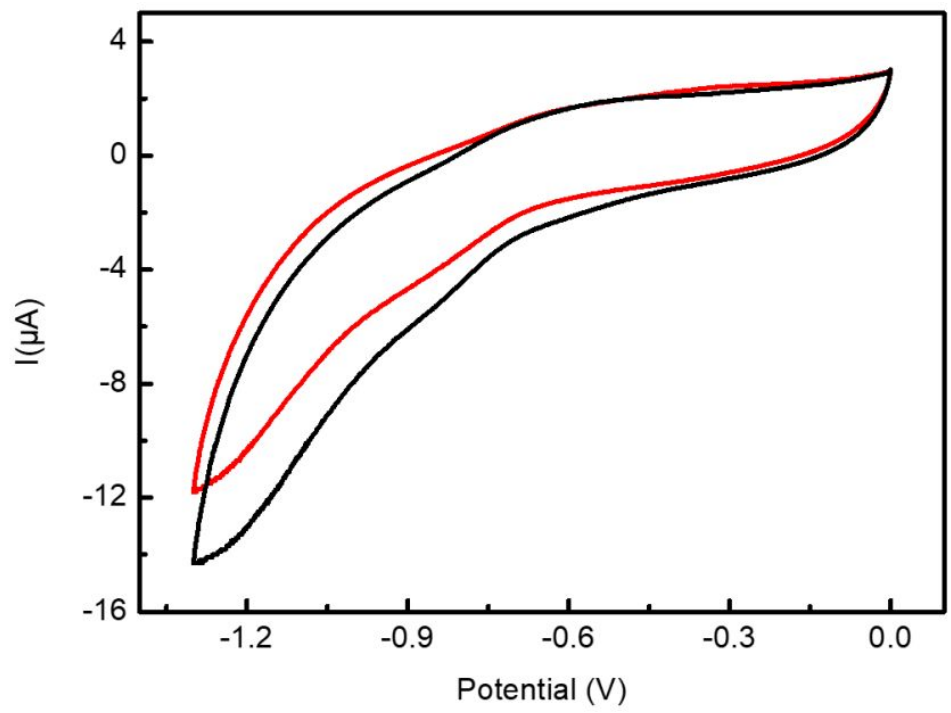

Figure S2. Cyclic voltammograms of uranyl-spiked water (contain $1 \mathrm{M} \mathrm{NaCl}$ ) with the concentration of 0 ppm (black), an 8 ppm (red).

We conducted the cyclic voltammograms (CV) from -1.3 to $0 \mathrm{~V}$ to reveal the state of uranium state. GPAF-13 powder attached glassy carbon electrode (GCE) was used as the negative electrode and carbon rod was used as the positive electrode. As shown in Figure S2, there is no obvious oxidation-reduction peak in CV spectrum, which represented the unchanged valence state for uranium $(+6)$ after electroextraction. 

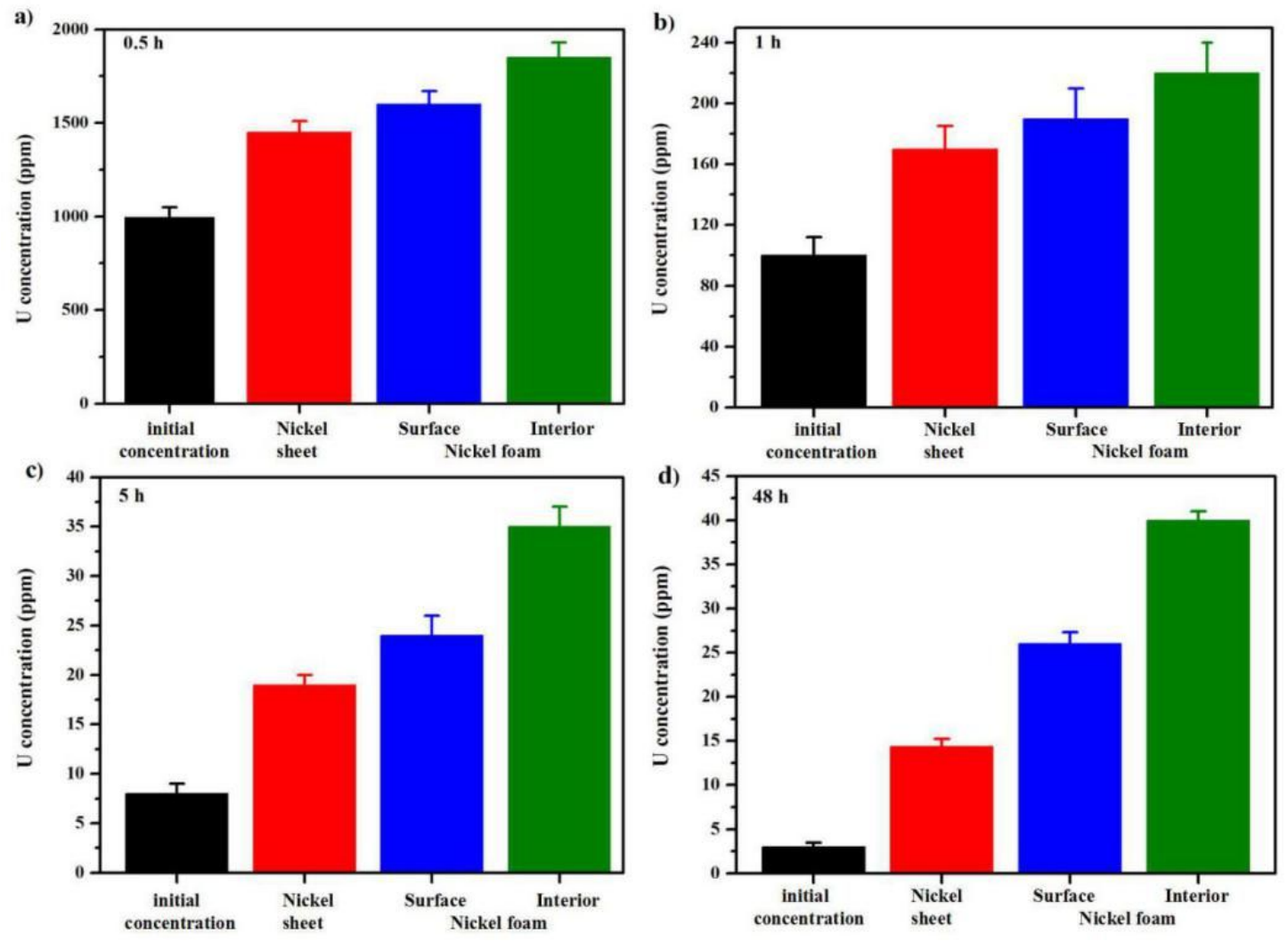

Figure S3. Maximum enrichment for uranyl ions from the uranyl-spiked real seawater with the initial uranyl concentration of (a) $1000 \mathrm{ppm}$, (b) $100 \mathrm{ppm}$, (c) $8 \mathrm{ppm}$, and (d) $3.3 \mathrm{ppb}$, by using AACE method. An a.c. voltage of $-1.3 \mathrm{~V}$ to $0.0 \mathrm{~V}$ was used with the duration time of the alternating potential of $-1.3 \mathrm{~V}$ to $0.0 \mathrm{~V}$ for $0.5 \mathrm{~ms}$ and $2 \mathrm{~ms}$, respectively.
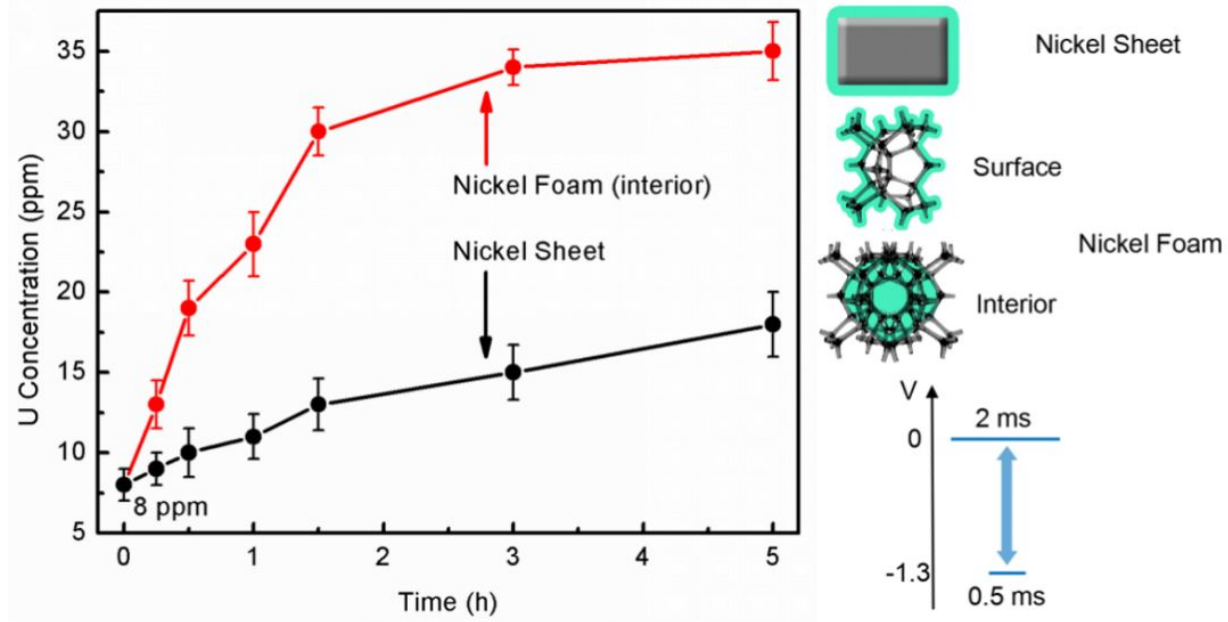

Figure S4. $\mathrm{UO}_{2}{ }^{2+}$ ion-enrichment isotherm from a spiked real seawater using the AACE method with an initial uranium concentration of $8 \mathrm{ppm}$. Under the AACE method, an a.c. voltage of $-1.3 \mathrm{~V}$ to $0.0 \mathrm{~V}$ was used with the duration time of the alternating potential of $-1.3 \mathrm{~V}$ to $0.0 \mathrm{~V}$ for $0.5 \mathrm{~ms}$ and $2 \mathrm{~ms}$, respectively. 


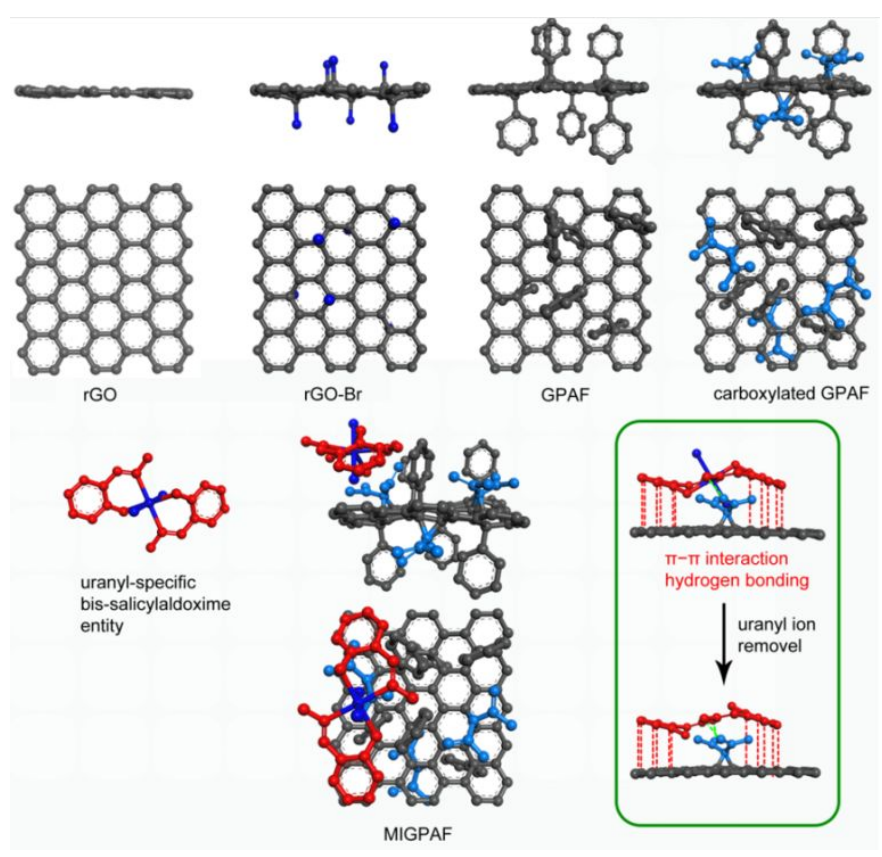

Figure S5. Snapshot from molecular dynamics showing the $\pi-\pi$ interaction of uranyl-specific bis-salicylaldoxime entity with the non-uniform graphene layer in the GPAFs architecture.

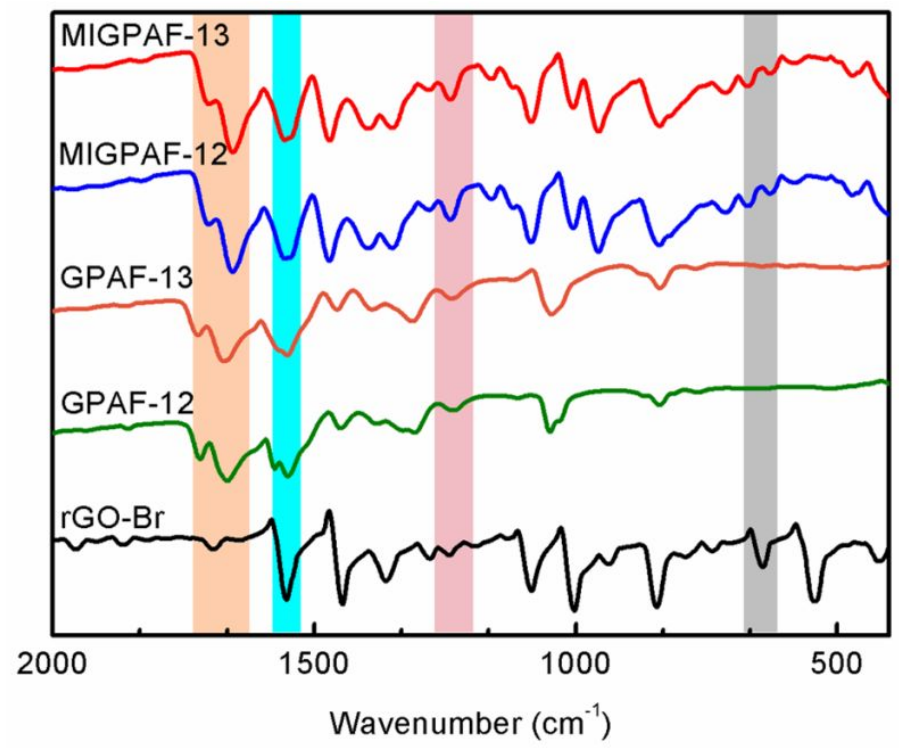

Figure S6. FT-IR spectra for rGO-Br (black), GPAF-12 (green), GPAF-13 (orange), MIGPAF-12 (blue), and MIGPAF-13 (red).

Malonic acid with adjacent carboxylic groups was used to immobilize the uranyl specific bis-salicylaldoxime entity. As illustrate in FTIR spectrum, the blueshift of $-\mathrm{OH}$ band (-COOH group from graphene layer) from 1233 to $1241 \mathrm{~cm}^{-1}$ and the redshift of $-\mathrm{C}=0$ band (salicylaldoxime ligand) from 1664 and $1721 \mathrm{~cm}^{-1}$ to 1658 and $1703 \mathrm{~cm}^{-1}$, respectively demonstrate the formation of hydrogen bonding. 


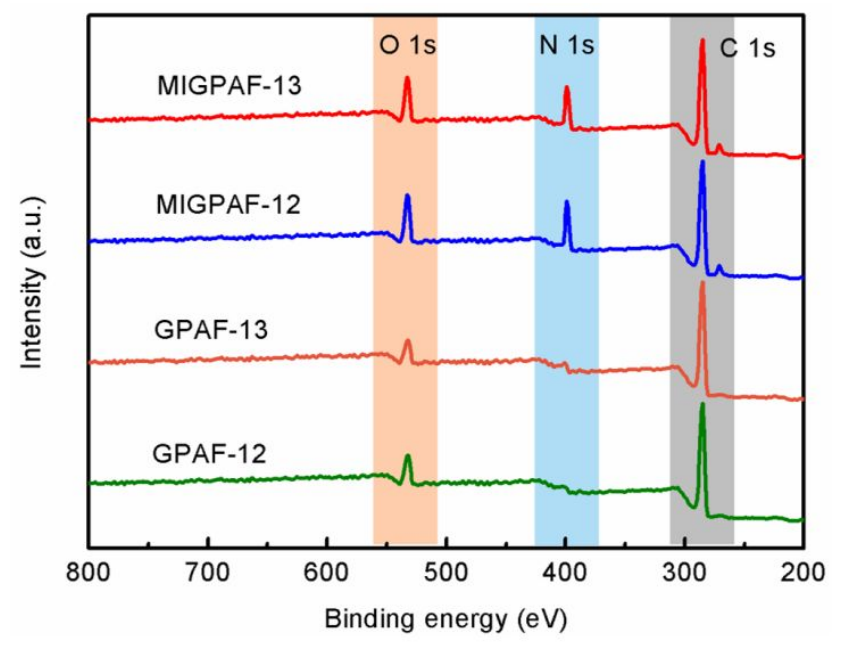

Figure S7. XPS spectra for GPAF-12 (green), GPAF-13 (orange), MIGPAF-12 (blue), and MIGPAF-13 (red).

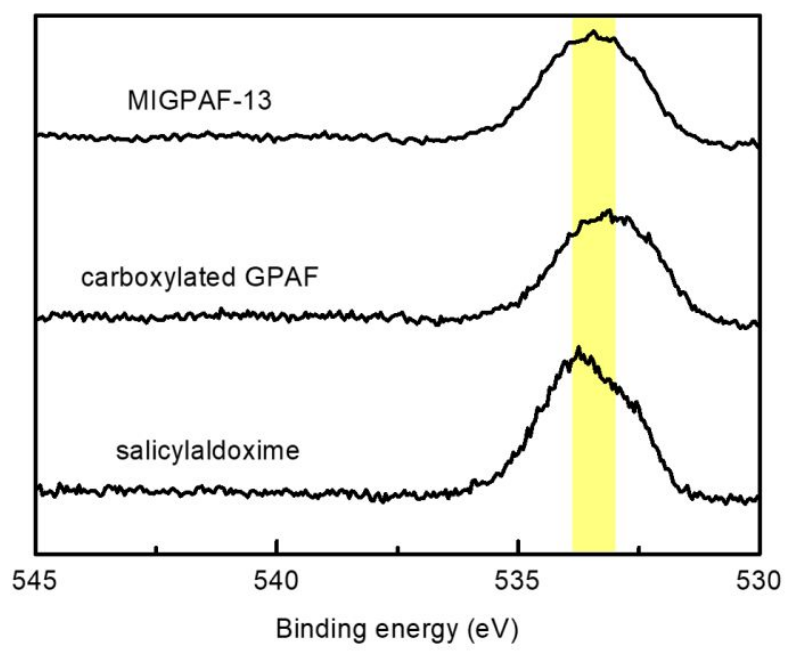

Figure S8. XPS $\left(\mathrm{O}_{1 s}\right)$ spectra for MIGPAF-13, carboxylated GPAF, and salicylaldoxime. 


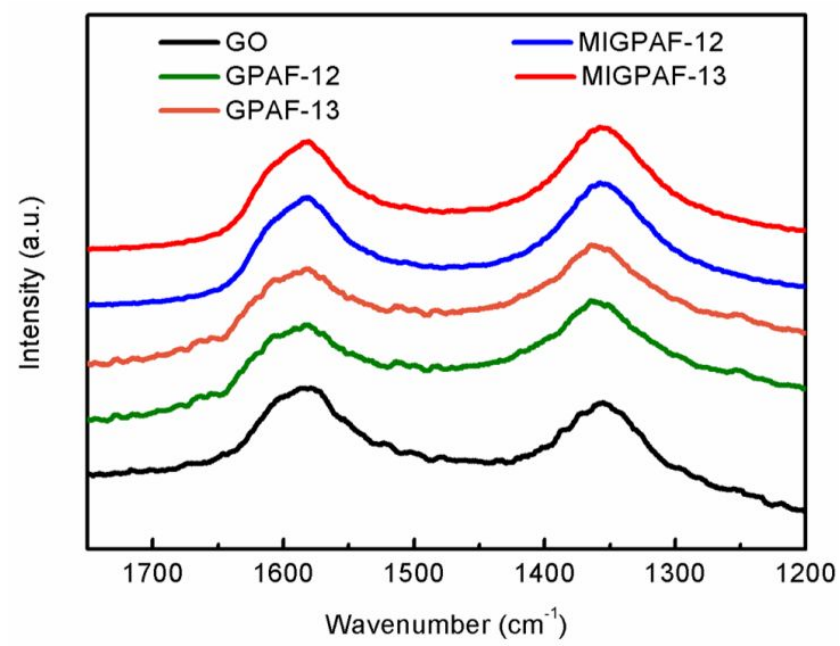

Figure S9. Raman spectra for GO (black), GPAF-12 (green), GPAF-13 (orange), MIGPAF-12 (blue), and MIGPAF-13 (red). 

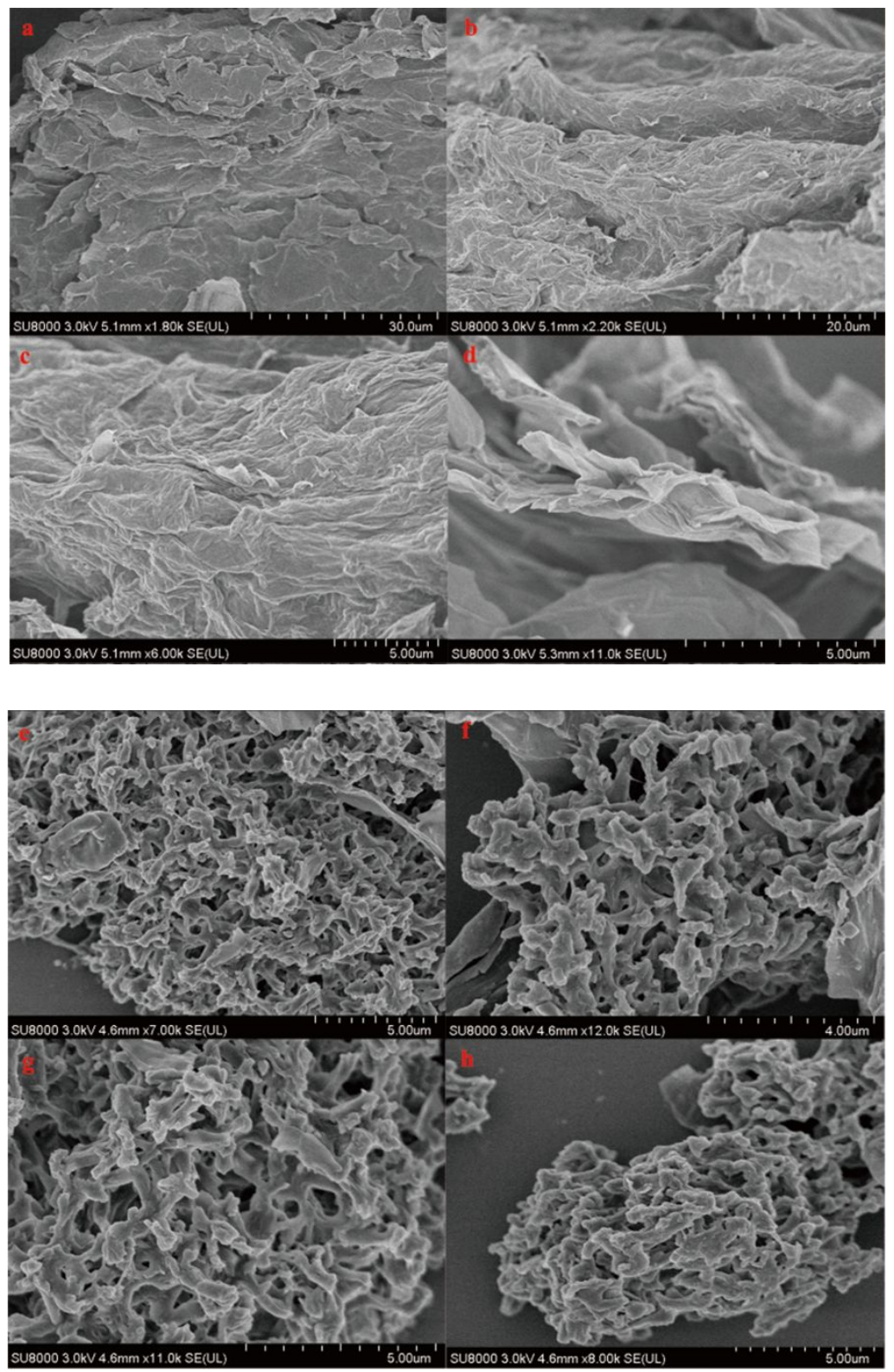

Figure S10. SEM images of GO (a), rGO-Br (b), MIG (c, d), GPAF-12 (e), GPAF-13 (f), MIGPAF-12 (g), and MIGPAF-13 (h). 

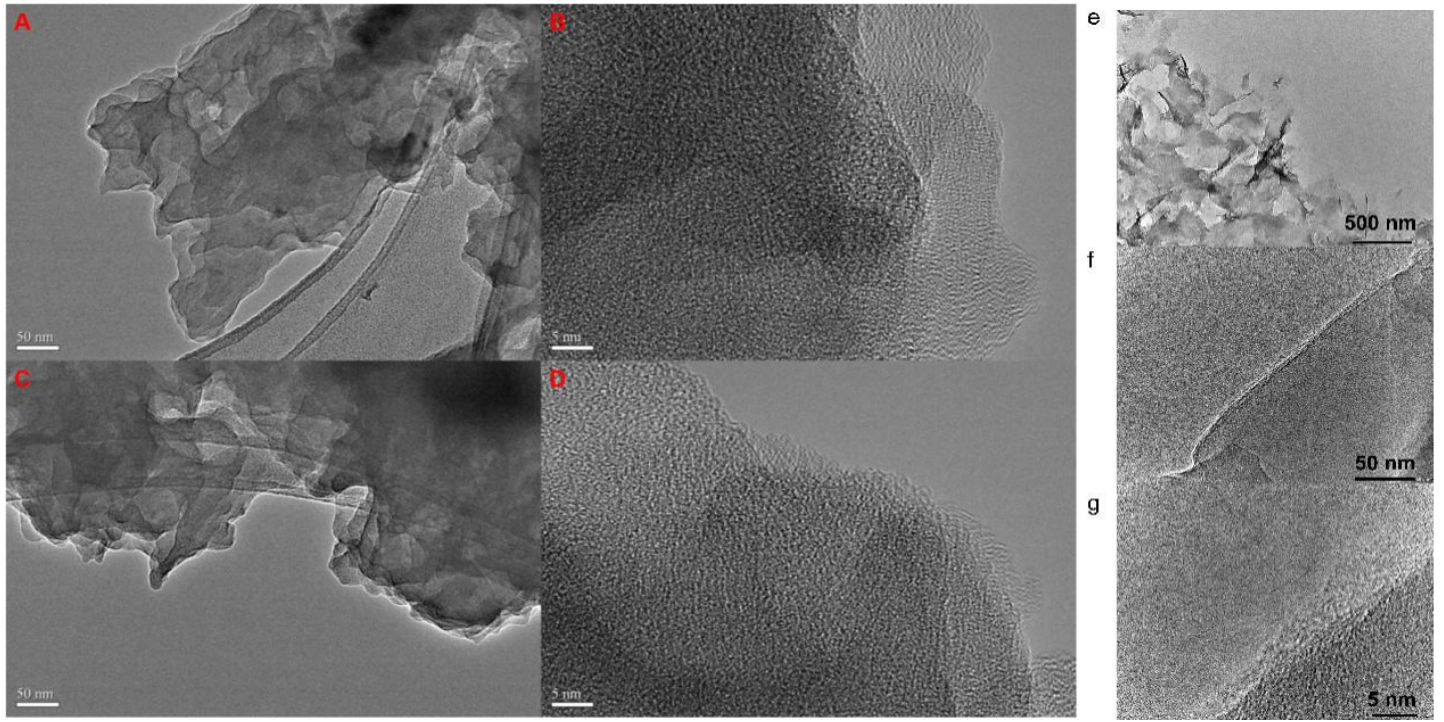

Figure S11. TEM images of MIGPAF-12 (A, B), and MIGPAF-13 (C, D). Conducting HR-TEM to visualize the layered structure of MIGPAF-13 (e-g).

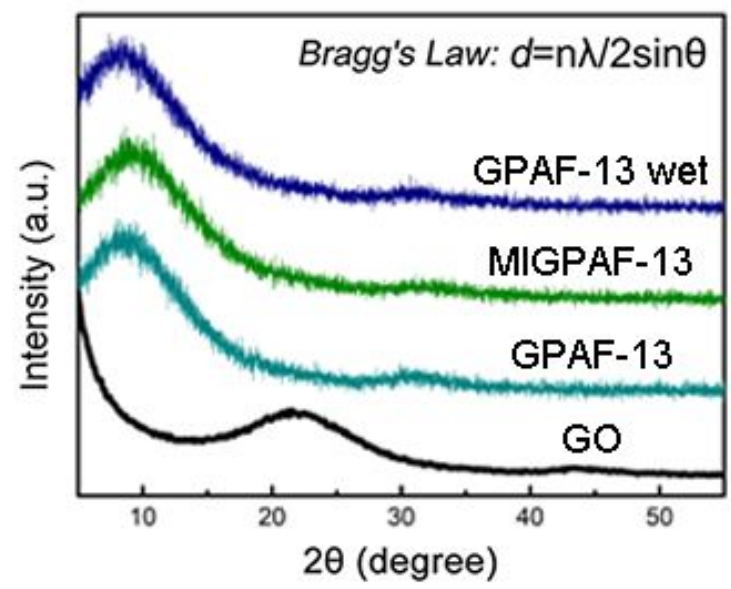

Figure S12. PXRD spectra of dry GPAF-13, dry MIGPAF-13, and wet GPAF-13. 

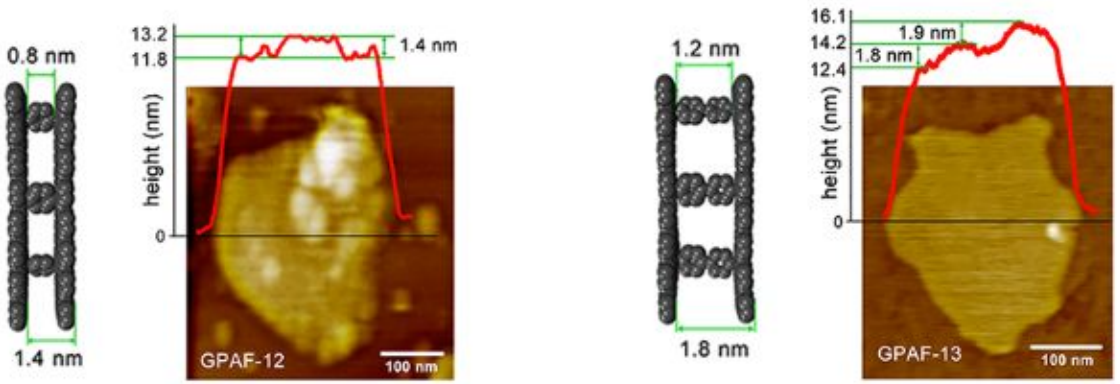

Figure S13. AFM images and height profiles for GPAF-12 and GPAF-13, respectively.

To verify the pillared structure of the GPAFs, atomic force microscopy (AFM) was conducted at the edge of the GPAFs particles. After ultrasonic treatment in ethanol for $1 \mathrm{~h}$, the thicknesses of GPAF-12 were 11.8 and $13.2 \mathrm{~nm}$.

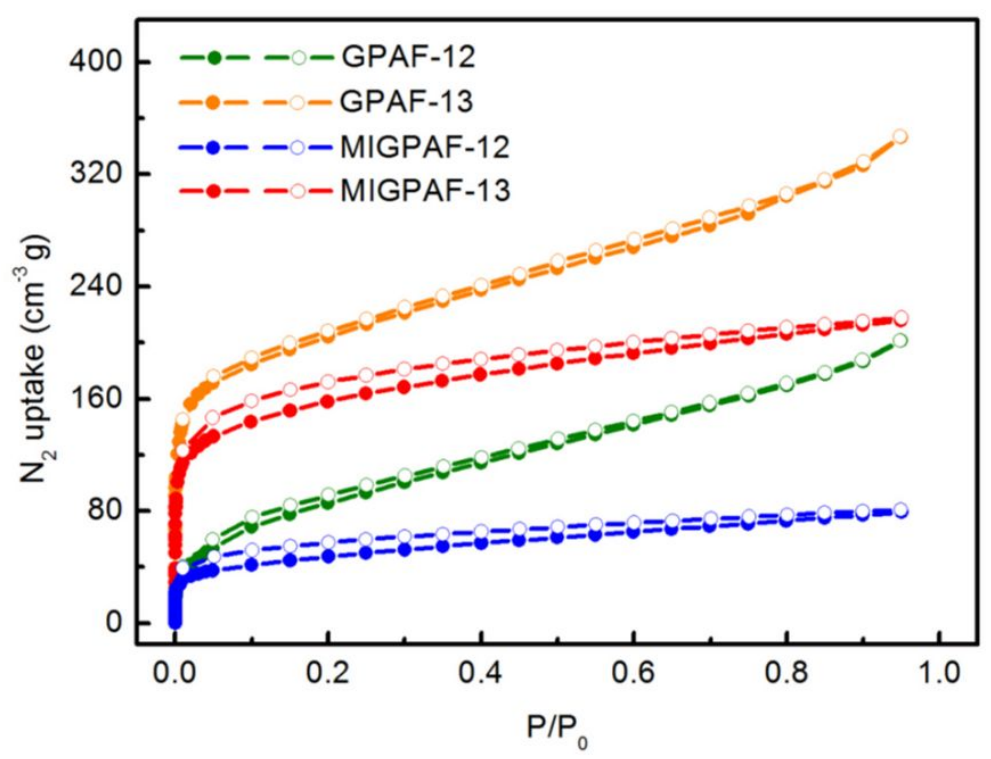

Figure S14. $\mathrm{N}_{2}$ sorption isotherms of GPAF-12, GPAF-13, MIGPAF-12, and MIGPAF-13. 


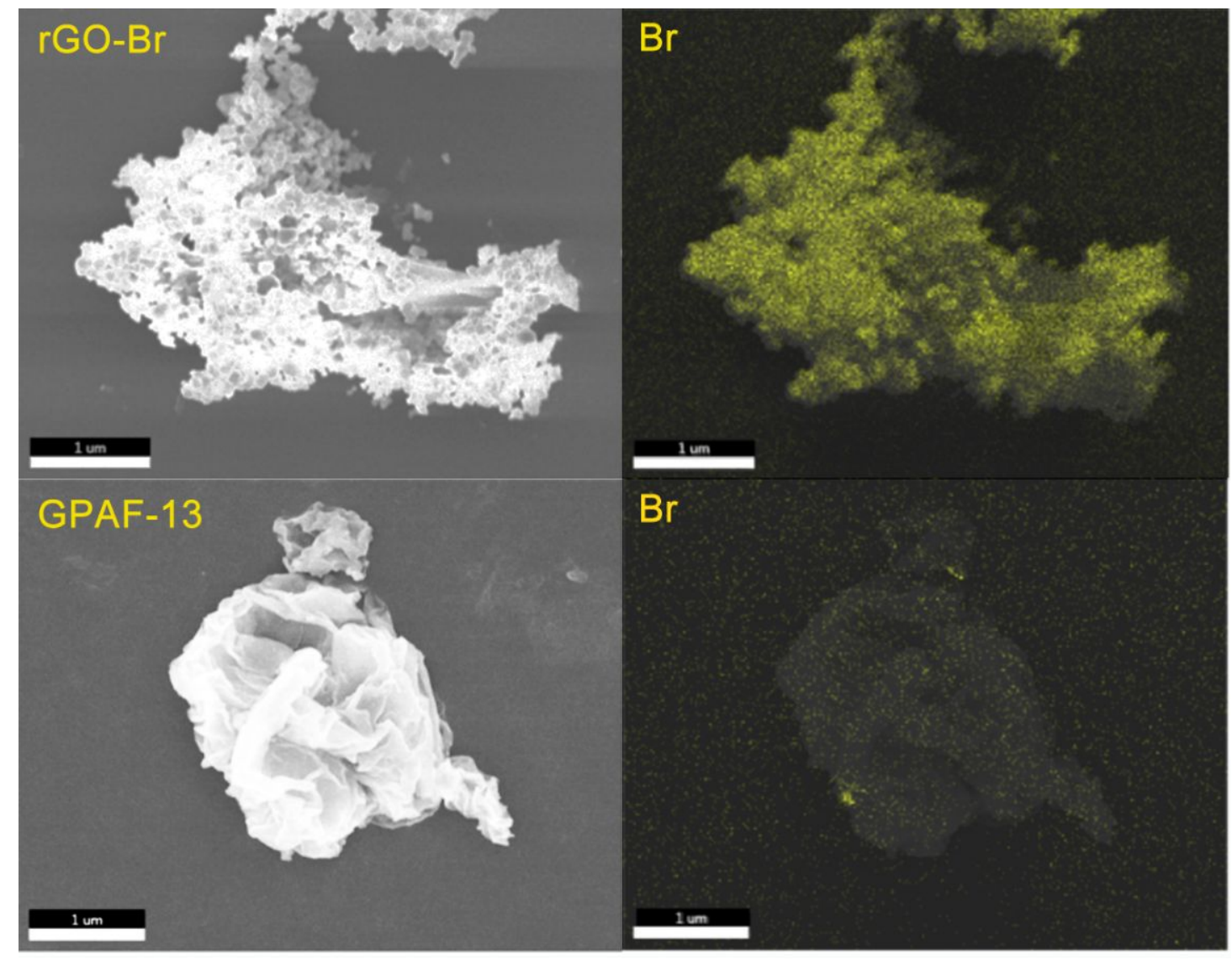

Figure S15. Element mapping (Br) images of rGO-Br and GPAF-13.

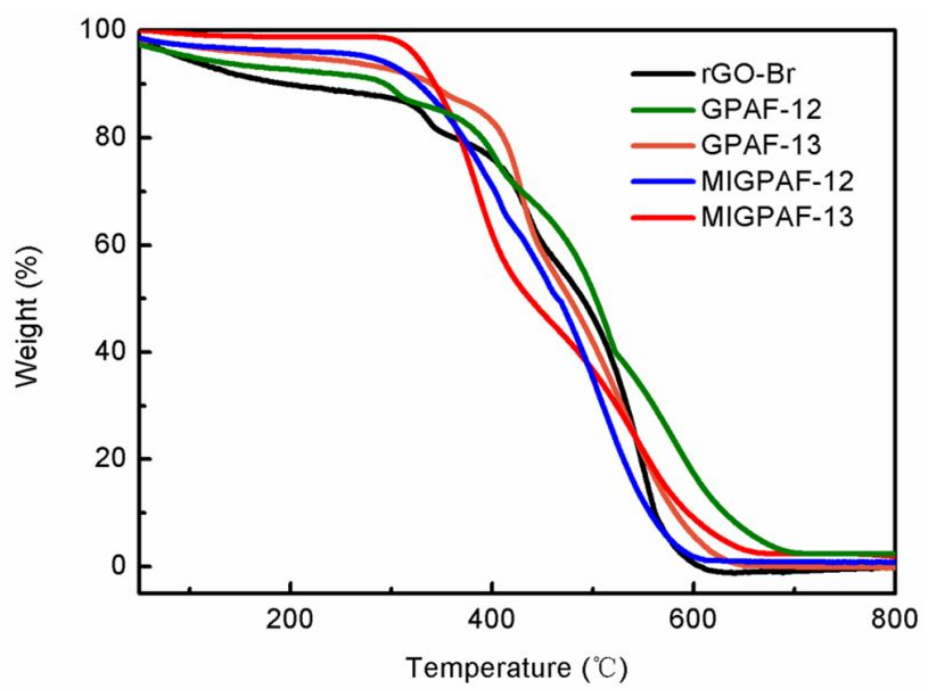

Figure S16. TGA curves for rGO-Br (black), GPAF-12 (green), GPAF-13 (orange), MIGPAF-12 (blue), and MIGPAF-13 (red). 

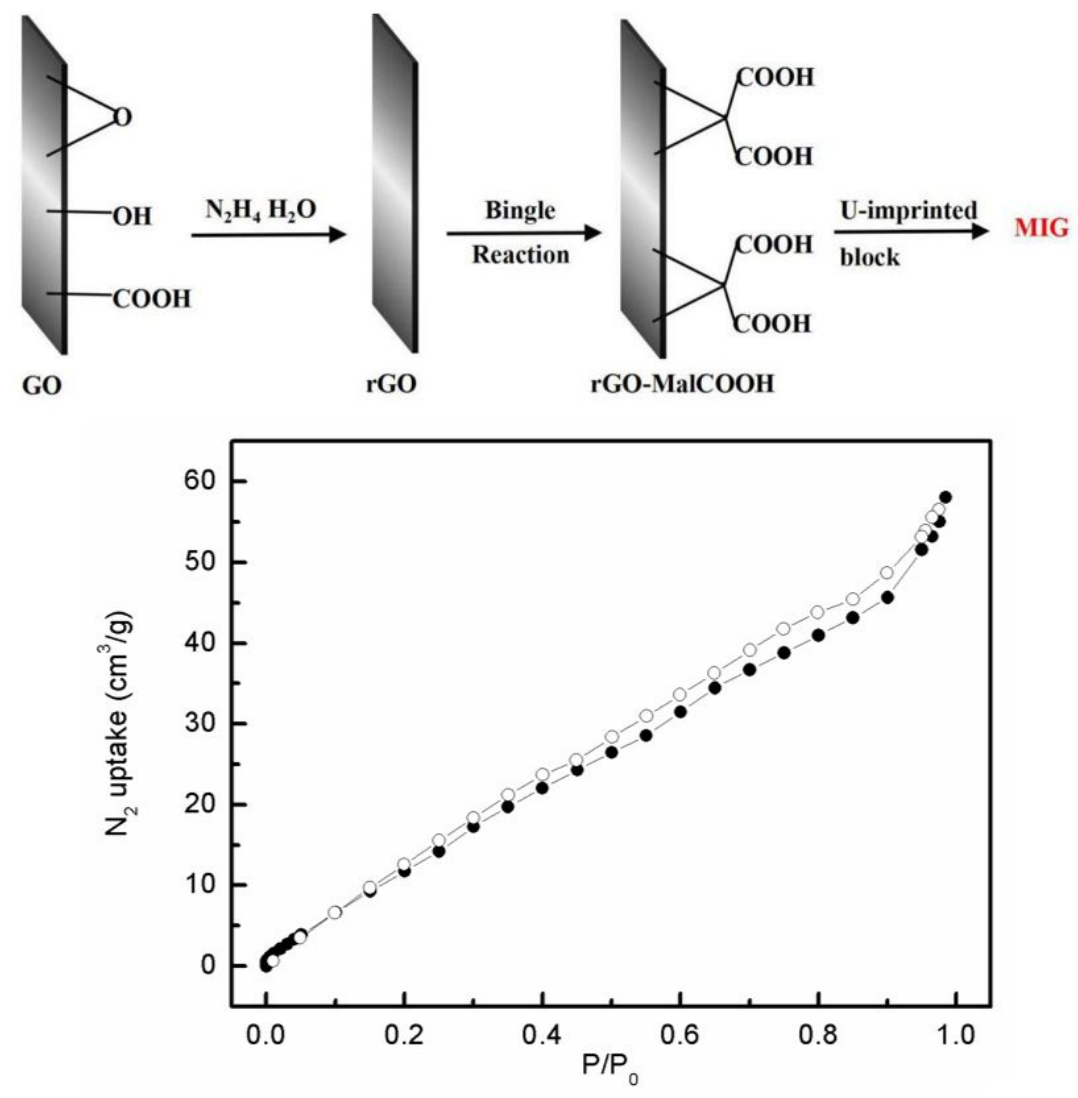

Figure S17. Synthesis routes for non-porous molecularly imprinted graphene (MIG) as the reference material, and $\mathrm{N}_{2}$ sorption isotherm of MIG. The BET surface area of MIG was calculated to be $25 \mathrm{~m}^{2} \mathrm{~g}^{-1}$.

According to the $\mathrm{N}$ element analysis ( $2.3 \mathrm{wt} \%)$, the bis-salicylaldoxime entity was calculated to be $1.64 \mathrm{mmol} / \mathrm{g}$, corresponding to the uranyl adsorption capacity was $\sim 195 \mathrm{mg} / \mathrm{g}$. 


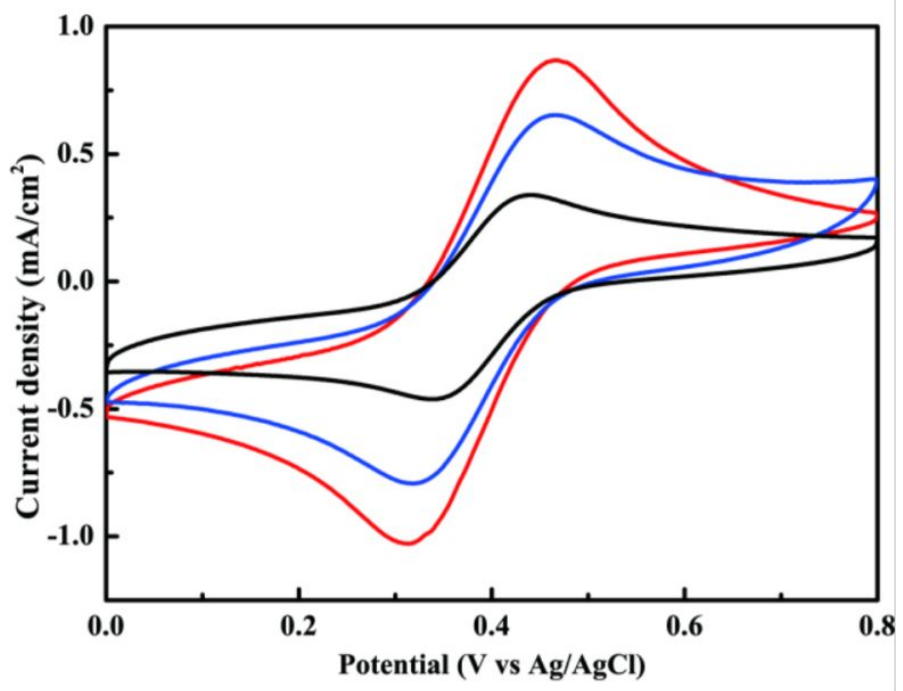

Figure S18. CV curves of GO (black), MIGPAF-12 (blue), and MIGPAF-13 (red) recorded in $1 \mathrm{M} \mathrm{KCl}$ aqueous solution containing $10 \mathrm{mM} \mathrm{K}_{4} \mathrm{Fe}(\mathrm{CN})_{6}$.
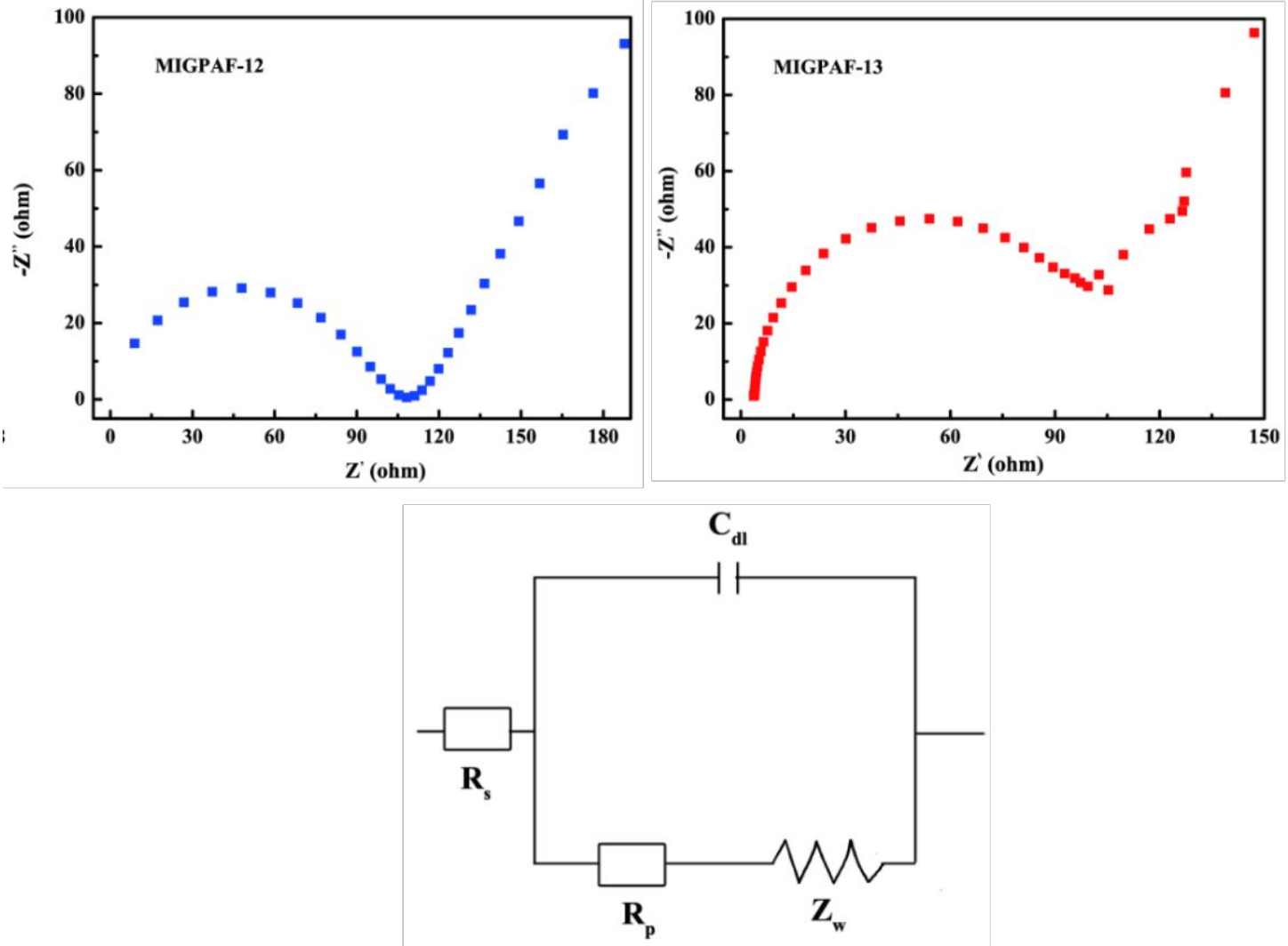

Figure S19. EIS spectra of MIGPAF-12 (blue), and MIGPAF-13 (red) in $1 \mathrm{M} \mathrm{KCl}$ aqueous solution containing $10 \mathrm{mM} \mathrm{K}_{4} \mathrm{Fe}(\mathrm{CN})_{6}$. The equivalent circuit of the MIGPAF electrochemical impedance measurement system. 

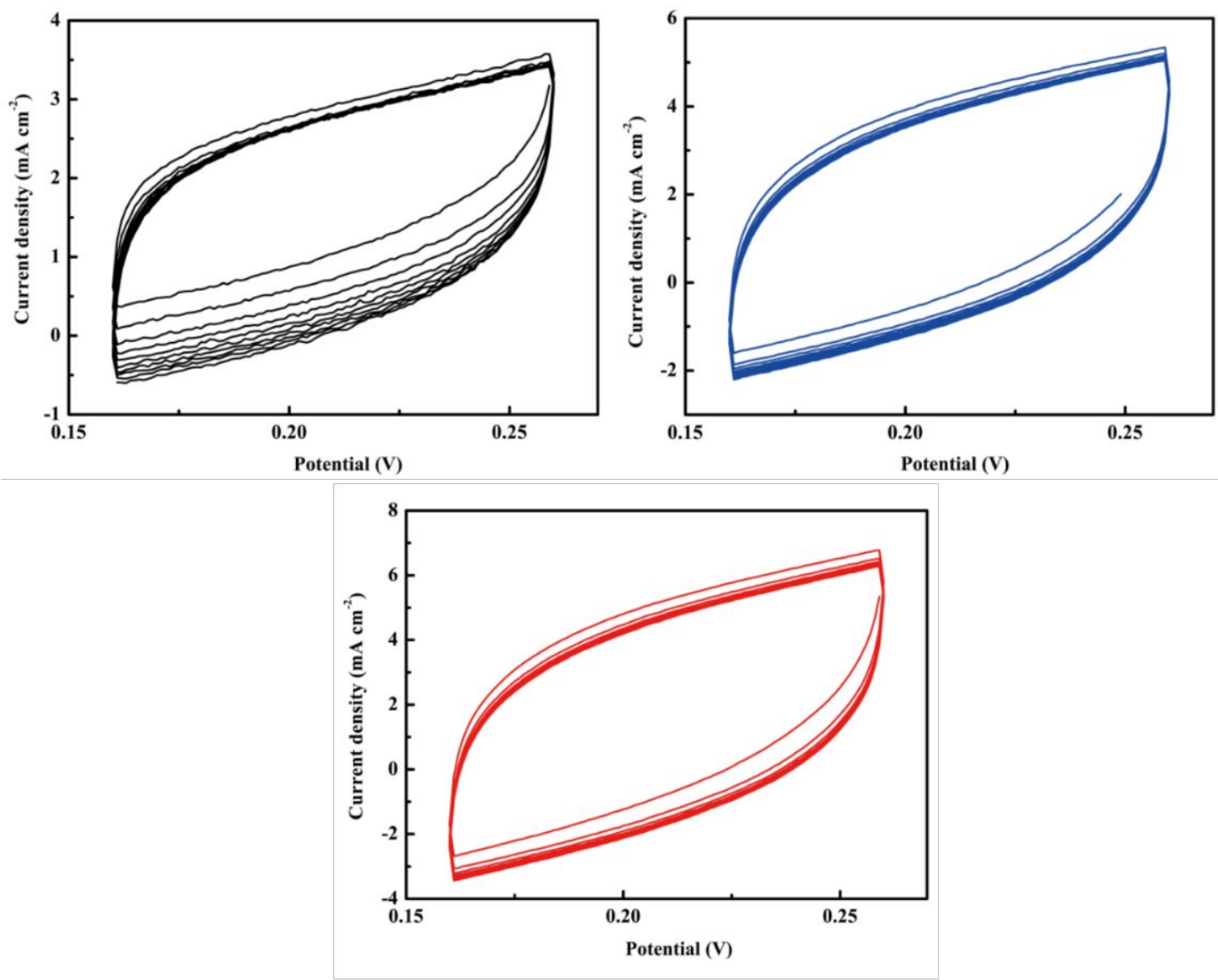

Figure S20. CV curves of GO (black), MIGPAF-12 (blue), and MIGPAF-13 (red) in a uranyl-spiked real seawater with an initial concentration of $8 \mathrm{ppm}$.

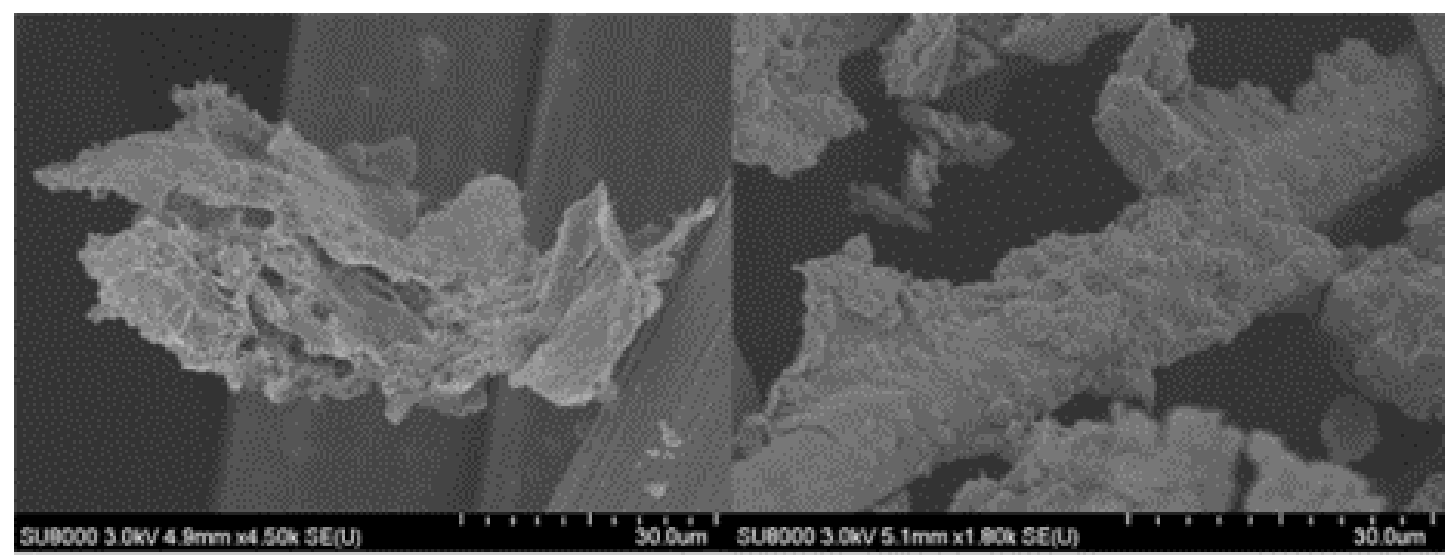

Figure S21. SEM images of MIGPAF-13 attached on a carbon felt. 

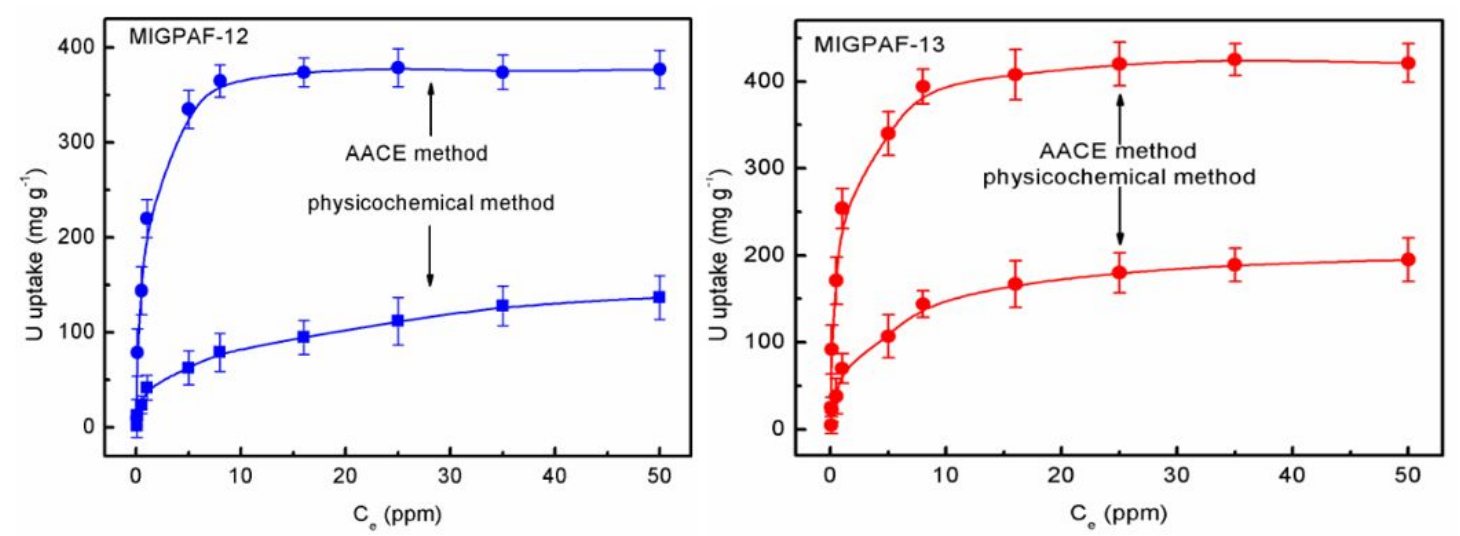

Figure S22. Uranyl ion uptake using AACE method compared with the physicochemical method with an initial uranyl concentration ranged from $5 \mathrm{ppb}$ to $50 \mathrm{ppm}$ after $30 \mathrm{~min}$ contact.

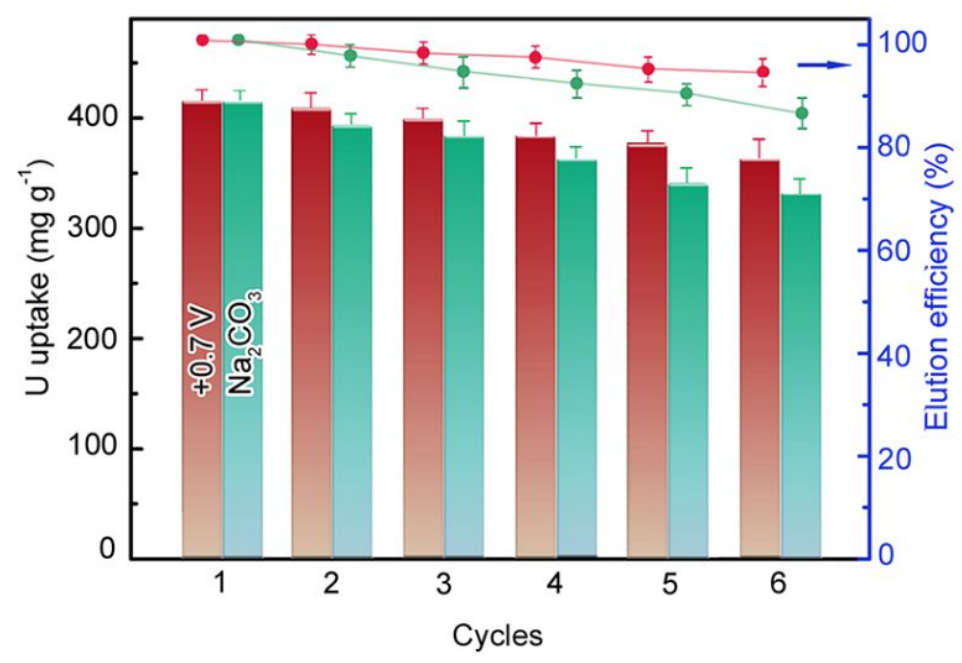

Figure S23. Recycling experiment of MIGPAF-13 (initial concentration of 8 ppm).

MIGPAF-13 was impregnated in $200 \mathrm{~mL}$ of $8 \mathrm{ppm}$ uranyl-spiked real seawater for $2 \mathrm{~h}$ under the AACE method to obtain the exhausted sample, denoted as MIGPAF-13@U (uranium capacity of $411.6 \mathrm{mg} \mathrm{g}^{-1}$ ). Taking a different approach, electrochemically mediated repulsion provides a great potential for the facile release of adsorbed ions. For the analysis of the release kinetics, an oxidizing potential ( $+0.7 \mathrm{~V}$ ) was constantly applied for $90 \mathrm{~min}$ to release the bound uranyl ions. MIGPAF-13@U revealed an obviously quicker release ( $>82 \%$ after a $45 \mathrm{~min}$ test and $>95 \%$ in $90 \mathrm{~min}$ ) out of the MIGPAF structure in comparison with the chemically mediated elution method $\left(0.1 \mathrm{M} \mathrm{Na}_{2} \mathrm{CO}_{3}\right)$. In addition, MIGPAF-13 maintained its adsorptive capacity after six uranyl adsorption-desorption cycles, with a final uptake capacity of $374.4 \mathrm{mg} \mathrm{g}^{-1}$ and elution efficiency over $91 \%$. In contrast, the chemically mediated elution $\left(0.1 \mathrm{M} \mathrm{Na}_{2} \mathrm{CO}_{3}\right)$ showed a gradually decreasing performance after six cycles, exhibiting a final uranyl capacity of $333.1 \mathrm{mg} \mathrm{g}^{-1}$ and elution efficiency of $87 \%$. 


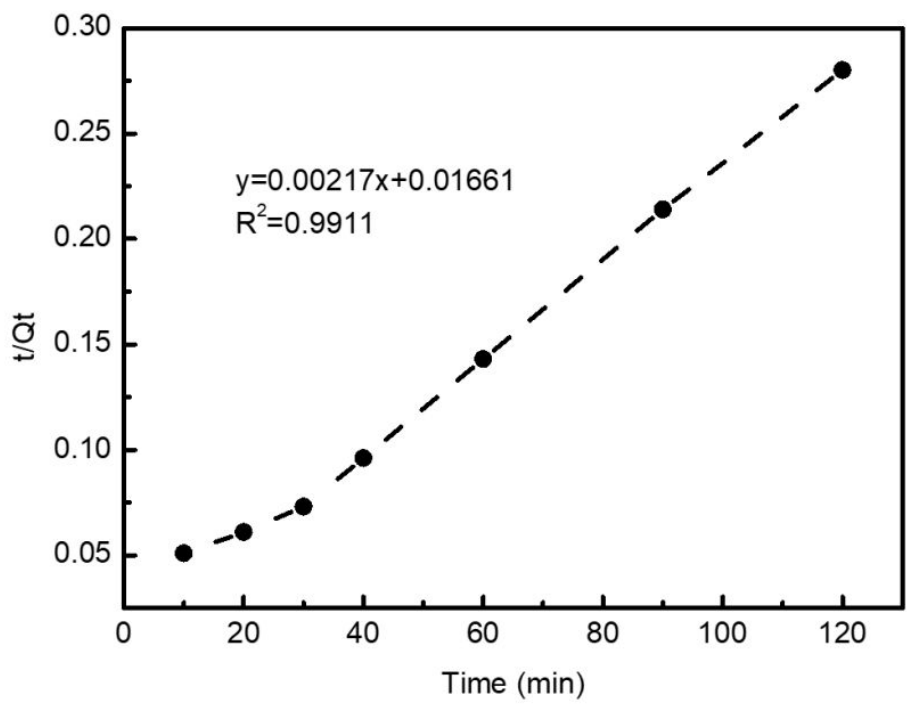

Figure S24. The pseudo-second-order kinetics plot for MIGPAF-13 under AACE method with the initial uranyl concentration of $8 \mathrm{ppm}$.
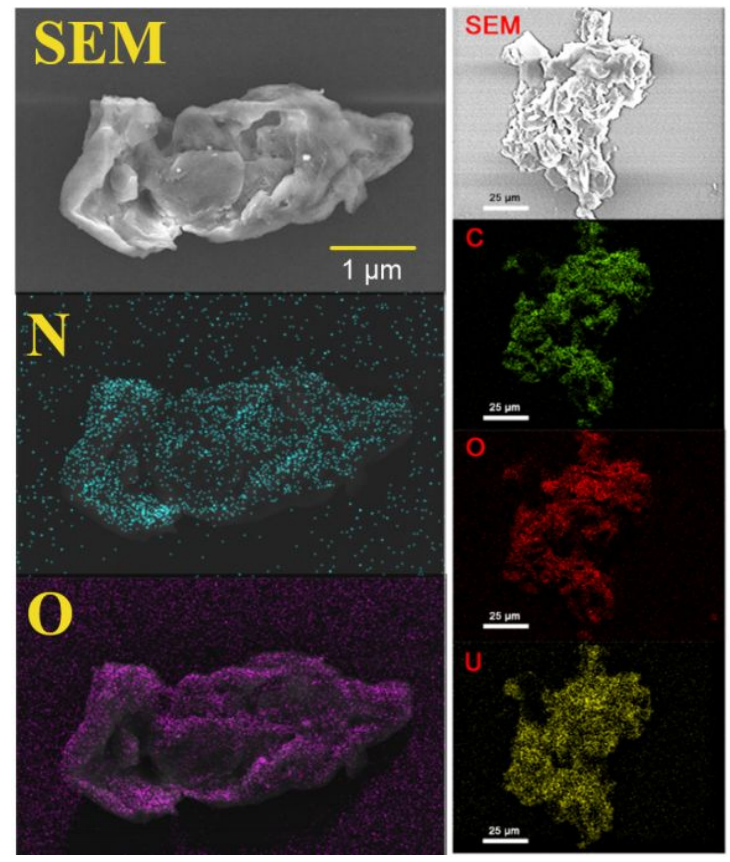

Figure S25. SEM and element mapping images of MIGPAF-13 and MIGPAF13@U. 

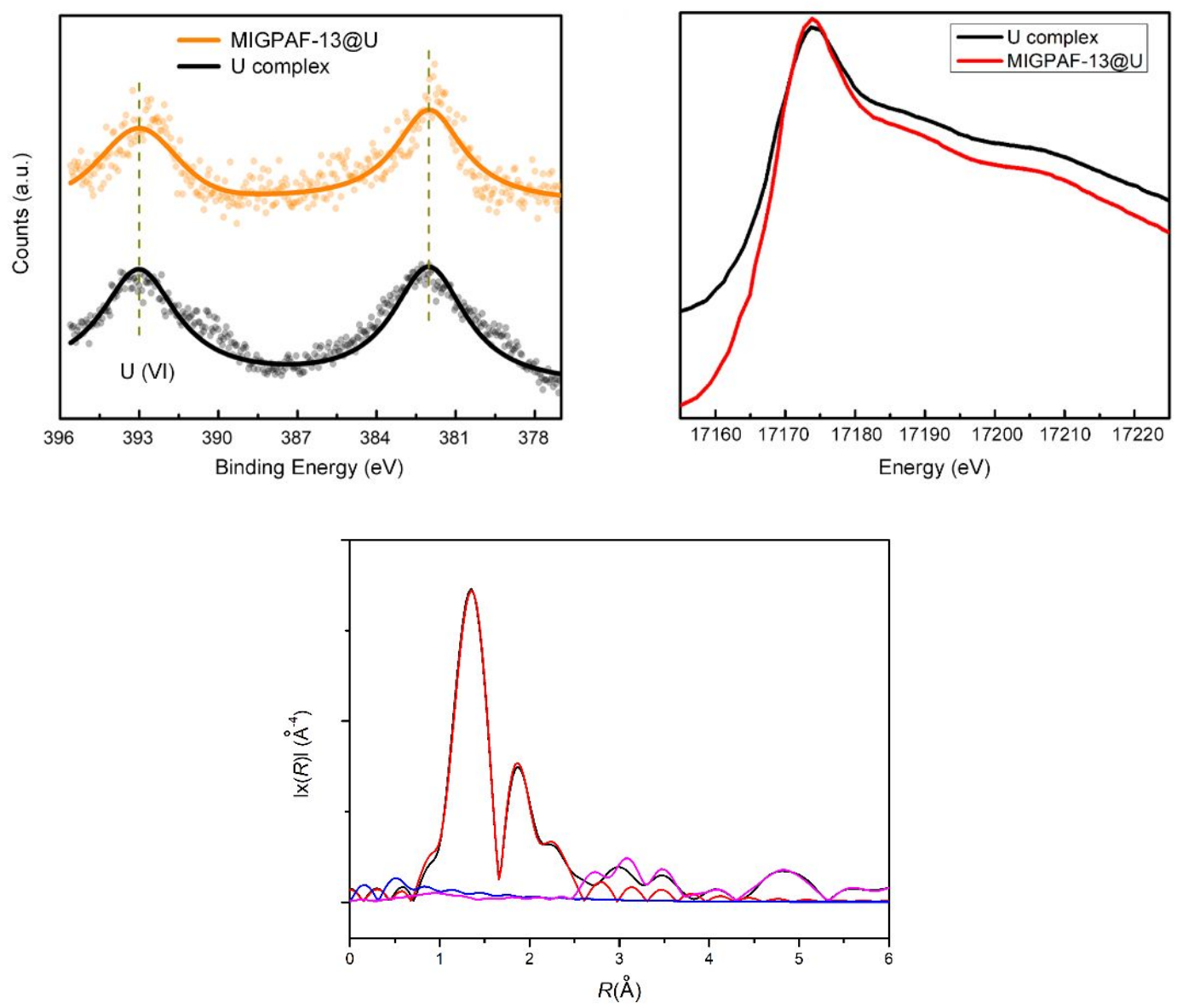

Figure S26. left) High-resolution XPS $U_{4 f}$ spectra of MIGPAF-13@U and U complex. right) Near-edge regions of the uranium L3-edge absorption spectra for U-complex and MIGPAF-13@U collected from X-ray absorption fine structure (XAFS) spectroscopy.

EXAFS data and fits for c U@POP-A0, d U@POP-pNH2-A0, and e U@POPoNH2AO. The graphical depiction of the amidoxime species is displayed by each fit for clarity. The magnitude of the Fourier transform is plotted in black, the real space component in blue, and fits in solid and dashed red, respectively. In all plots the inset is the $\mathrm{k} 3$-weighted $\chi(\mathrm{k})$ data and corresponding fit. 


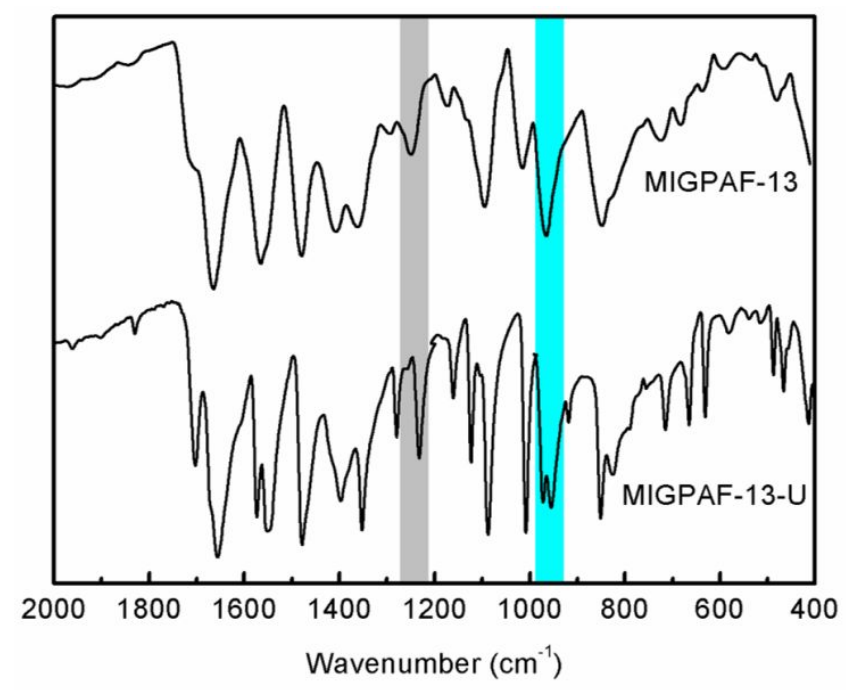

Figure S27. FT-IR spectra for MIGPAF-13 and MIGPAF-13@U.

As for MIGPAF-13@U, the shift for -OH band from 1241 to $1230 \mathrm{~cm}^{-1}$ and the shift for -N-O- band from 967 to $953 \mathrm{~cm}^{-1}$ were assigned to the -U-O coordination band between $\mathrm{UO}_{2}{ }^{2+}$ ion and oxime group in salicylaldoxime. Moreover, the new peak at $971 \mathrm{~cm}^{-1}$ was assigned to the -U-O band of uranyl ion loaded on MIGPAF13.

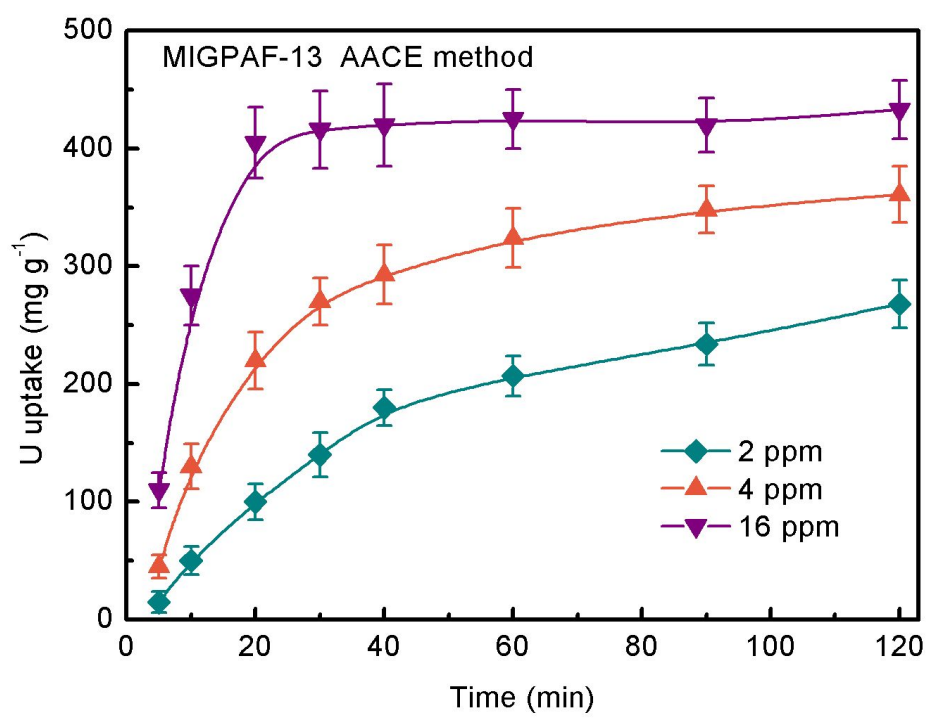

Figure S28. Uranium uptake of MIGPAF-13 using the AACE method with the initial uranium concentrations of 2,4 , and $16 \mathrm{ppm}$. 


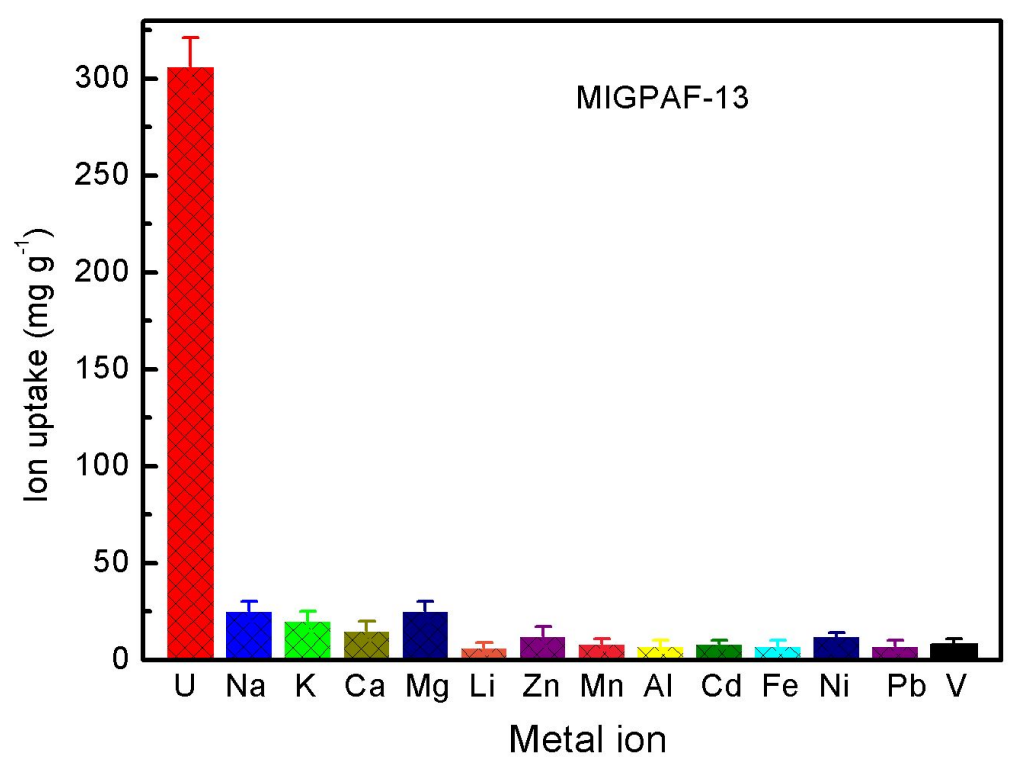

Figure S29. Metal ions uptake of the MIGPAF-13 in uranyl spiked real seawater contain 8 ppm of $\mathrm{UO}_{2}{ }^{2+}, \mathrm{Li}^{+}, \mathrm{Zn}^{2+}, \mathrm{Mn}^{2+}, \mathrm{Al}^{3+}, \mathrm{Cd}^{2+}, \mathrm{Cu}^{2+}, \mathrm{Fe}^{3+}, \mathrm{Ni}^{2+}, \mathrm{Pb}^{2+}, \mathrm{VO}_{3}$, and $8873 \mathrm{ppm}$ of $\mathrm{Na}^{+}, 1039 \mathrm{ppm}$ of $\mathrm{Mg}^{2+}, 401 \mathrm{ppm}$ of $\mathrm{Ca}^{2+}, 724 \mathrm{ppm}$ of $\mathrm{K}^{+}$.

To investigated the selectivity of MIGPAF-13, the MIGPAF powder (3 $\mathrm{mg}$ ) attached carbon felt electrode was tested in a spiked real seawater $\left(8 \mathrm{ppm} \mathrm{UO}_{2}{ }^{2+}\right.$,

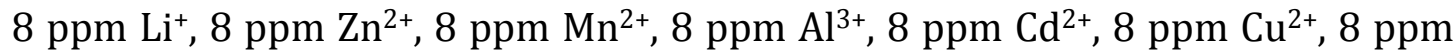

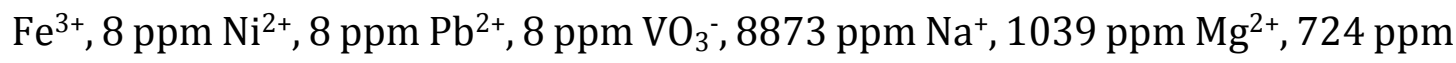
$\mathrm{K}^{+}$, and $401 \mathrm{ppm} \mathrm{Ca}^{2+}$ ). After extraction under bias and standing another 15 minutes, the ions enriched near the carbon felt respread to seawater. The carbon felt electrode is taken out, and dried by a hair dryer. Then, the carbon felt electrode is put into water $(50 \mathrm{~mL})$, a constant oxidizing potential of $+0.7 \mathrm{~V}$ is applied to the carbon felt electrode for up to $2 \mathrm{~h}$ at room temperature with a gently stirring. The concentration of ions is afforded by ICP-MS, shown in Figure S29. 


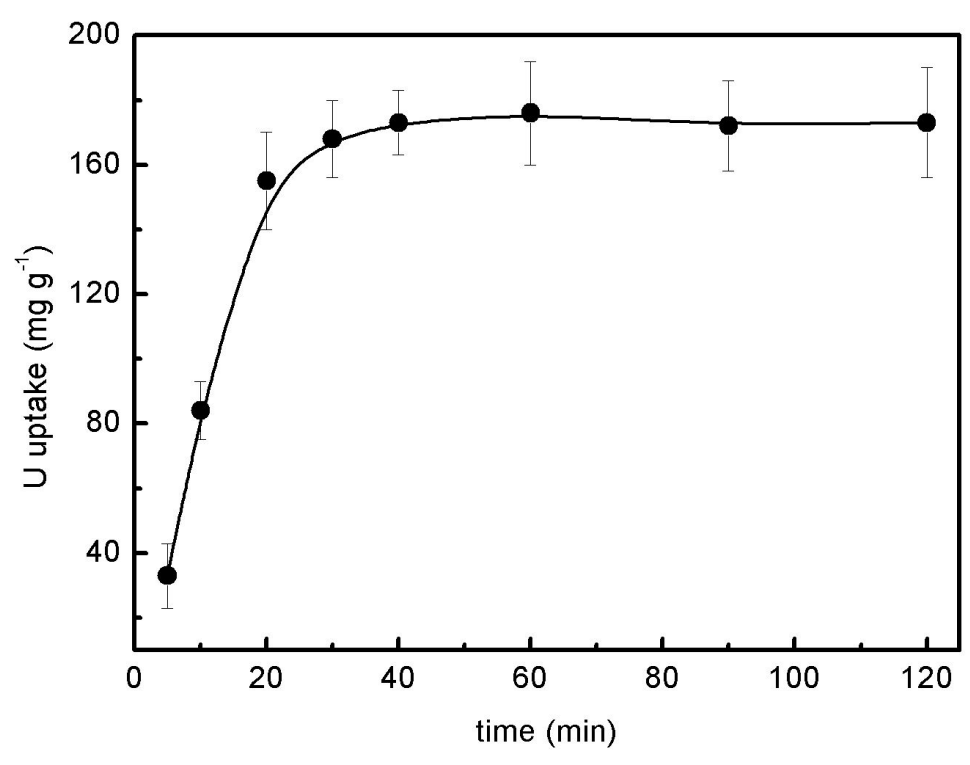

Figure S30. Uranium uptake of MIG using the AACE method with the initial uranium concentration of $8 \mathrm{ppm}$.

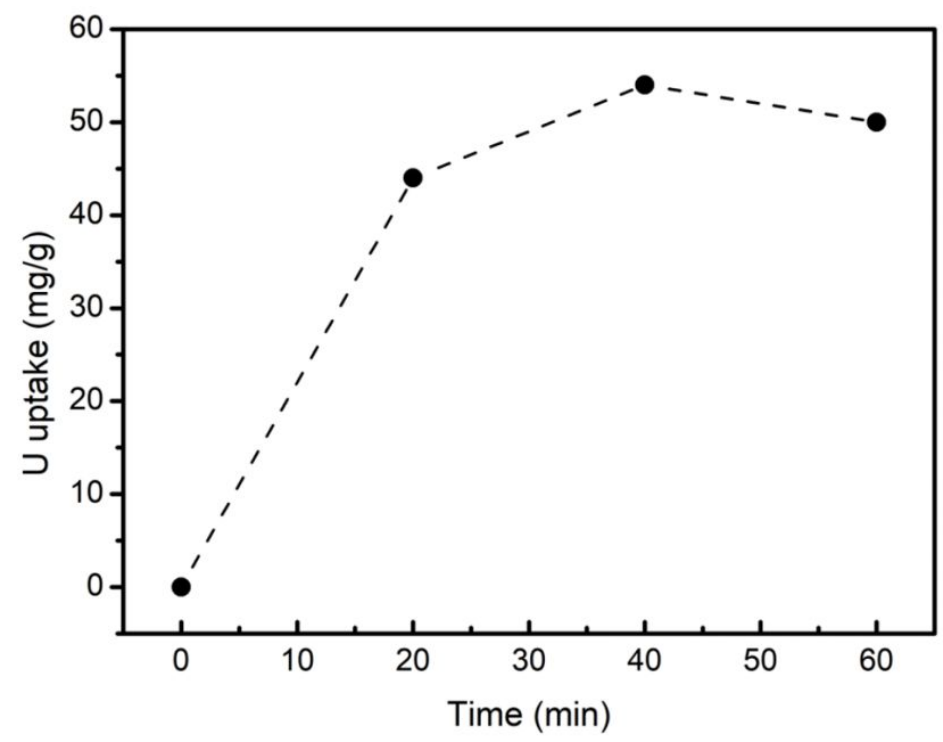

Figure S31. Uranium uptake experiments using GPAF-13 without the uranylspecific bis-salicylaldoxime entity with an initial uranium concentration of $8 \mathrm{ppm}$. Under the AACE process, GPAF-13 sample was determined to reveal maximum uranium capacity of $c a .55 \mathrm{mg} / \mathrm{g}$ after $60 \mathrm{~min}$ contact. This augmentation of MIGPAF-13 (419.2 $\mathrm{mg} \mathrm{g}^{-1}$ ) is ascribed to the fact that the subtle binding sites (uranyl-specific bis-salicylaldoxime entity) facilitates the capture of uranyl ions. 

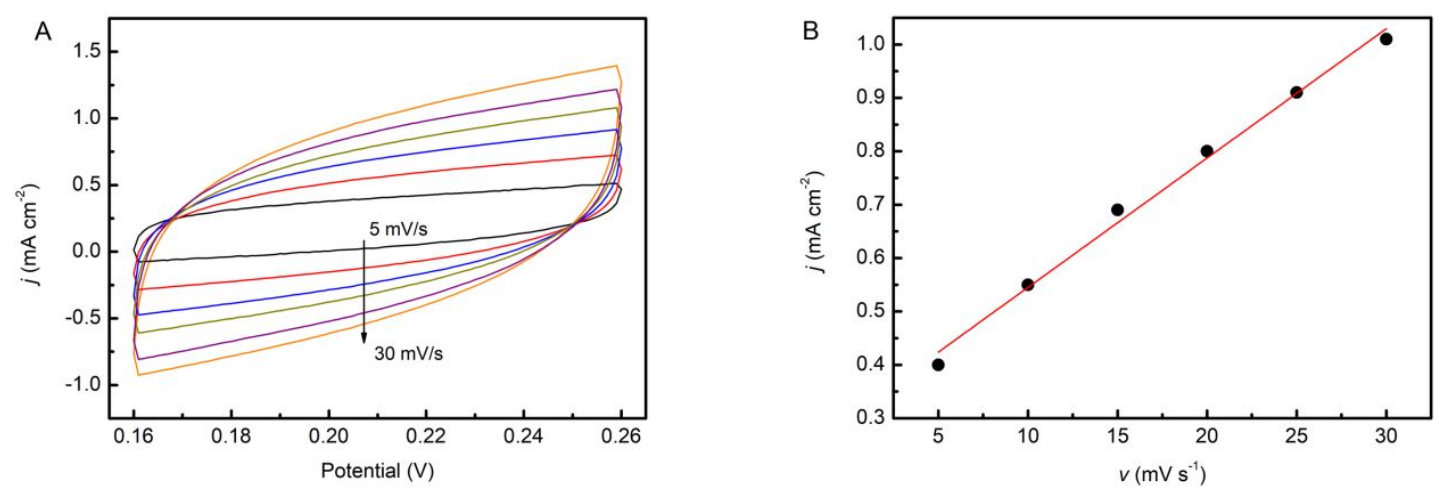

Figure S32. (A) CV profiles of GPAF-13 in $\mathrm{H}_{2} \mathrm{SO}_{4}(0.5 \mathrm{M})$ solution. (B) Current density plotted against scan rates.

The glass carbon electrode modified with GPAFs is used as the working electrode, the $\mathrm{Ag} / \mathrm{AgCl}$ electrode and a Pt wire are used as reference and counter electrodes, respectively. The electrochemically active surface areas (ECSAs) were determined by cyclic voltammograms (CVs) at a potential window of 0.16-0.26 V with different scan rates of $5,10,15,20,25$, and $30 \mathrm{mV} / \mathrm{s}$. The double layer capacitance (Cdl) was estimated by plotting the $\mathrm{j}$ at $0.21 \mathrm{~V}$ against the scan rate, and the linear slope is the double layer capacitance Cdl, is used to represent ECSA (the double layer capacitance of the clean graphite is $20 \mu \mathrm{F} / \mathrm{cm}^{2}$ ). Correspondingly, the ECSA of GPAF-12 and GPAF-13 can be calculated as 49 and $26 \mathrm{~cm}^{2}$. 
Supporting Information Tables

Table S1 Nitrogen element analysis of GPAFs samples.

\begin{tabular}{|c|c|}
\hline Material & Elemental analysis (wt\%) \\
\hline GPAF-12 & 0.1 \\
\hline GPAF-13 & 0.1 \\
\hline MIGPAF-12 & 3.6 \\
\hline MIGPAF-13 & 4.2 \\
\hline
\end{tabular}

Table S2 Concentration of the metal ions in natural seawater used in this study.

\begin{tabular}{|c|c|c|}
\hline Metal & Concentration & Unit \\
\hline $\mathbf{K}$ & 723.9 & $\mathrm{ppm}$ \\
\hline $\mathbf{N a}$ & 8873.2 & $\mathrm{ppm}$ \\
\hline $\mathbf{C a}$ & 400.6 & $\mathrm{ppm}$ \\
\hline $\mathbf{M g}$ & 1038.8 & $\mathrm{ppm}$ \\
\hline $\mathbf{C u}$ & 3.7 & $\mathrm{ppb}$ \\
\hline $\mathbf{F e}$ & 3.7 & $\mathrm{ppb}$ \\
\hline $\mathbf{N i}$ & 4.8 & $\mathrm{ppb}$ \\
\hline $\mathbf{Z n}$ & 15.1 & $\mathrm{ppb}$ \\
\hline $\mathbf{U}$ & 3.3 & $\mathrm{ppb}$ \\
\hline $\mathbf{V}$ & 3.2 & $\mathrm{ppb}$ \\
\hline
\end{tabular}

Table S3 Materials used for uranyl ion uptake from natural seawater.

\begin{tabular}{|c|c|c|c|}
\hline Materials & $\begin{array}{c}\text { Time } \\
\text { (day) }\end{array}$ & U uptake $\mathbf{m g ~ g}^{-1}$ ) & Reference \\
\hline MIGPAF-13 & 28 & 8.01 & This work \\
\hline $\begin{array}{c}\text { PPA@MISS-PAF- } \\
\mathbf{1}\end{array}$ & 56 & 16.20 & This work \\
\hline $\begin{array}{c}\text { Zn'+PA0 } \\
\text { hydrogel }\end{array}$ & 28 & 13.00 & Chem 2020, 6, 1683 \\
\hline PAF-CS & 60 & 9.23 & $\begin{array}{c}\text { Adv. Mater. 2020, 32, } \\
1906615\end{array}$ \\
\hline PAO PNMs & 35 & 8.92 & Chem. Sci. 2020, 11, 4747 \\
\hline ZIF-8/SAP & 35 & 9.35 & $\begin{array}{c}\text { Nano Energy 2020, 71, } \\
104629\end{array}$ \\
\hline AO-NHTs & 30 & 6.99 & $\begin{array}{c}\text { ACS Appl. Mater. } \\
\text { Interfaces 2020, 12, } \\
18012\end{array}$ \\
\hline
\end{tabular}




\begin{tabular}{|c|c|c|c|}
\hline BP-PAO & 56 & 11.76 & $\begin{array}{c}\text { Angew. Chem. Int. Ed. } \\
\mathbf{2 0 2 0}, 591220\end{array}$ \\
\hline Anti-UiO-66 & 30 & 4.62 & $\begin{array}{c}\text { Adv. Sci. 2019, 6, } \\
1900002\end{array}$ \\
\hline PAO hydrogel & 28 & 4.87 & $\begin{array}{c}\text { Adv. Sci. 2019, 6, } \\
1900085\end{array}$ \\
\hline UUS-1 & $48 \mathrm{~h}$ & 9.46 & $\begin{array}{c}\text { Adv. Sci. 2019, 6, } \\
1900961\end{array}$ \\
\hline MS@PID0/Alg & 56 & 5.84 & $\begin{array}{c}\text { Adv. Funct. Mater. 2019, } \\
29,1901009\end{array}$ \\
\hline [NH4 $^{+}$][COF-S0 \\
]
\end{tabular}

Table S4 Power consumption and electricity cost during the test was summarized. The price of electricity used was $¥ 0.575$ yuan/kWh (Changchun, China).

\begin{tabular}{|c|c|c|}
\hline Voltage/V & Power/W & Daily Cost/¥ \\
\hline $\mathbf{1 . 3}$ & 0.00085 & $1.17 \times 10^{-5}$ \\
\hline $\mathbf{1 . 3}$ & 0.00070 & $0.96 \times 10^{-5}$ \\
\hline \multirow{2}{*}{ Average } & $\sim$ & $1.07 \times 10^{-5}(¥)$ \\
& & $1.65 \times 10^{-6}(\$)$ \\
\hline
\end{tabular}

Table S5 Economic cost for fabrication of MIGPAF-13 using raw materials.

\begin{tabular}{|c|c|c|c|}
\hline Raw material & Price per unit & Quantity & Total price \\
\hline GO & $¥ 2200 / 100 \mathrm{~g}$ & $10 \mathrm{~g}$ & $¥ 220$ \\
\hline Uranium & $¥ 250 / 300 \mathrm{~g}$ & $10 \mathrm{~g}$ & $¥ 10$ \\
\hline Salycilaldoxime & $¥ 690 / 1000 \mathrm{~g}$ & $10 \mathrm{~g}$ & $¥ 7$ \\
\hline NaOH & $¥ 1450 / 1 \mathrm{t}$ & $100 \mathrm{~g}$ & $\sim$ \\
\hline Sodium chloroacetate & $¥ 72 / 500 \mathrm{~g}$ & $100 \mathrm{~g}$ & $¥ 14.4$ \\
\hline $\mathbf{A g N O}_{3}$ & $¥ 297 / 25 \mathrm{~g}$ & $10 \mathrm{~g}$ & $¥ 119$ \\
\hline $\mathbf{N a}_{\mathbf{2}} \mathbf{S}_{\mathbf{2}} \mathbf{0}_{3}$ & $¥ 250 / 500 \mathrm{~g}$ & $50 \mathrm{~g}$ & $¥ 25$ \\
\hline $\mathbf{N B S}^{\text {Dimethyl }}$ & $¥ 93 / 100 \mathrm{~g}$ & $100 \mathrm{~g}$ & $¥ 93$ \\
\hline bromomalonate & $¥ 2500 / 100 \mathrm{~g}$ & $10 \mathrm{~g}$ & $¥ 250$ \\
\hline DBU & $¥ 232 / 500 \mathrm{~g}$ & $100 \mathrm{~g}$ & $¥ 47$ \\
\hline $\mathbf{4 , 4}$ - & $¥ 450 / 5 \mathrm{~g}$ & $5 \mathrm{~g}$ & $¥ 450$ \\
\hline
\end{tabular}




\begin{tabular}{|c|c|c|c|}
\hline $\begin{array}{c}\text { Biphenyldiyldiboronic } \\
\text { acid }\end{array}$ & & & \\
\hline Trifluoroacetic acid & $¥ 82 / 100 \mathrm{~g}$ & $10 \mathrm{~g}$ & $¥ 8.2$ \\
\hline Catalyst & $¥ 5600 / 100 \mathrm{~g}$ & $10 \mathrm{~g}$ & $¥ 560$ \\
\hline Labor cost & $\sim$ & $\sim$ & $¥ 100$ \\
\hline Total & $\sim$ & $\sim$ & $\begin{array}{c}¥ 1903.6 / 11.7 \\
\mathbf{\$ 2 6 7 / 1 1 . 7} \mathbf{g}\end{array}$ \\
\hline
\end{tabular}

In this work, MIGPAF-13 on the carbon clothes is $c a .20 \mathrm{mg}$, which costs $c a$. $\$ 0.046$.

According to the report (http://www. chinanea. cn/site/content/38474. html), the cost of uranium-ores is $\leq \mathbf{\$ 2 6 0} / \mathbf{k g}-\mathbf{U}$.

According to the small-scale experimental results, the uptake uranium mass would be $c a$. $0.14 \mathrm{mg}$ after 28 days. The energy consumption of $\$ 4.62 * 10^{-5}$, which suggested the price of $U$ extraction from seawater is $\$ \mathbf{0 . 3 3} / \mathbf{g}-\mathbf{U}$.

Table S6 Nitrogen element analysis of MIGPAF-13 samples.

\begin{tabular}{|c|c|}
\hline Material & Elemental analysis (wt\%) \\
\hline MIGPAF-13-1 & 4.5 \\
\hline MIGPAF-13-3 & 4.4 \\
\hline MIGPAF-13-3 & 4.3 \\
\hline
\end{tabular}

X means the MIGPAF-13 after X times uranyl adsorption-desorption cycles. 
Table S7 Summary of Crystal Data and Refinement Results for [( $\left.\left.\mathrm{UO}_{2}\right)(\mathrm{SA})_{2}\left(\mathrm{H}_{2} \mathrm{O}\right)\right]$.

\begin{tabular}{|c|c|}
\hline Empirical formula & C14 H12 N2 O7 U \\
\hline Formula weight & 558.29 \\
\hline Crystal system & Monoclinic \\
\hline Space group & $P 2_{1 / \mathrm{m}}$ \\
\hline$a(\AA)$ & $8.8942(8)$ \\
\hline$b(\AA)$ & $6.9013(7)$ \\
\hline$c(\AA)$ & $13.3093(11)$ \\
\hline$a(\mathrm{deg})$ & 90 \\
\hline$b$ (deg) & $103.423(3)$ \\
\hline$g(\mathrm{deg})$ & 90 \\
\hline Volume $\left(\AA^{3}\right)$ & $794.63(13)$ \\
\hline$Z$ & 2 \\
\hline $\mathrm{D}_{\text {cala }}\left(\mathrm{mg} / \mathrm{m}^{3}\right)$ & 2.333 \\
\hline Crystal size $\left(\mathrm{mm}^{3}\right)$ & $0.220 \times 0.200 \times 0.180$ \\
\hline$F(000)$ & 516 \\
\hline$\mu(\mathrm{Mo} \mathrm{K} \alpha) /\left(\mathrm{mm}^{-1}\right)$ & 10.253 \\
\hline Completeness to theta & $25.242^{\circ}$ \\
\hline Reflections collected & 8582 \\
\hline Independent reflections & $1645[\mathrm{R}(\mathrm{int})=0.0788]$ \\
\hline Parameters & 182 \\
\hline $\mathrm{R}(\mathrm{int})$ & 0.0788 \\
\hline$\Delta(\rho)\left(\mathrm{e} \AA^{-3}\right)$ & 2.752 and -2.154 \\
\hline goodness of fit & 0.870 \\
\hline $\mathrm{R}^{\mathrm{a}}$ & $0.0444(0.0586)^{\mathrm{b}}$ \\
\hline $\mathrm{wR}_{2}{ }^{\mathrm{a}}$ & $0.1231(0.1523)^{\mathrm{b}}$ \\
\hline
\end{tabular}

${ }^{\mathrm{a}} \mathrm{R}=\Sigma|| \mathrm{F}_{0}|-| \mathrm{F}_{\mathrm{c}}|| / \Sigma\left|\mathrm{F}_{0}\right| ;$

$\mathrm{wR}_{2}=\left[\Sigma \mathrm{w}\left(\mathrm{F}_{0}^{2}-\mathrm{F}_{\mathrm{c}}^{2}\right)^{2} / \Sigma \mathrm{w}\left(\mathrm{F}_{\mathrm{o}}^{2}\right)^{2}\right]^{1 / 2}$;

$\left|F_{\mathrm{o}}\right|>4 \sigma\left(\left|\mathrm{F}_{\mathrm{o}}\right|\right)$.

${ }^{\mathrm{b}} \mathrm{On}$ the basis of all of the data. 
Table S8 Selected bond lengths $(\AA)$ and angles $(\mathrm{deg}) *$ for $\left[\left(\mathrm{UO}_{2}\right)(\mathrm{SA})_{2}\left(\mathrm{H}_{2} \mathrm{O}\right)\right]$.

\begin{tabular}{|c|c|c|c|c|c|c|c|}
\hline$C(1)-C(2)$ & 1.3900 & $\mathrm{C}(7)-\mathrm{H}(7)$ & 0.9300 & $O(1)-C(8)-C(9)$ & $118.8(13)$ & $\mathrm{O}(4)-\mathrm{N}(2)-\mathrm{U}(1)$ & $117.1(8)$ \\
\hline$C(1)-0(3)$ & $1.330(18)$ & $\mathrm{C}(14)-\mathrm{N}(1)$ & $1.264(16)$ & $O(1)-C(8)-C(13)$ & $121.2(13)$ & $\mathrm{N}(1)-\mathrm{O}(2)-\mathrm{H}(10)$ & $112(10)$ \\
\hline$C(2)-C(3)$ & 1.3900 & $\mathrm{C}(14)-\mathrm{H}(14)$ & 0.9300 & $C(9)-C(8)-C(13)$ & 120.0 & $\mathrm{~N}(2)-\mathrm{O}(4)-\mathrm{H}(20)$ & $136(10)$ \\
\hline $\mathrm{C}(2)-\mathrm{H}(2)$ & 0.9300 & $N(2)-O(4)$ & $1.422(14)$ & $C(10)-C(9)-C(8)$ & 120.0 & $\mathrm{C}(14)-\mathrm{N}(1)-\mathrm{O}(2)$ & $115.7(15)$ \\
\hline$C(3)-C(4)$ & 1.3900 & $\mathrm{~N}(2)-\mathrm{U}(1)$ & $2.578(13)$ & $\mathrm{C}(10)-\mathrm{C}(9)-\mathrm{H}(9)$ & 120.0 & $\mathrm{C}(14)-\mathrm{N}(1)-\mathrm{U}(1)$ & $126.7(12)$ \\
\hline $\mathrm{C}(3)-\mathrm{H}(3)$ & 0.9300 & $\mathrm{O}(2)-\mathrm{N}(1)$ & $1.325(15)$ & $\mathrm{C}(8)-\mathrm{C}(9)-\mathrm{H}(9)$ & 120.0 & $\mathrm{O}(2)-\mathrm{N}(1)-\mathrm{U}(1)$ & $117.2(10)$ \\
\hline$C(4)-C(5)$ & 1.3900 & $\mathrm{O}(2)-\mathrm{H}(10)$ & $0.84(2)$ & $C(9)-C(10)-C(11)$ & 120.0 & $O(7)-U(1)-O(6)$ & $176.8(7)$ \\
\hline $\mathrm{C}(4)-\mathrm{H}(4)$ & 0.9300 & $\mathrm{O}(4)-\mathrm{H}(20)$ & $0.84(2)$ & $\mathrm{C}(9)-\mathrm{C}(10)-\mathrm{H}(10)$ & 120.0 & $O(7)-U(1)-O(1)$ & $89.7(7)$ \\
\hline$C(5)-C(6)$ & 1.3900 & $\mathrm{O}(5)-\mathrm{U}(1)$ & $2.452(14)$ & $\mathrm{C}(11)-\mathrm{C}(10)-\mathrm{H}(10)$ & 120.0 & $O(6)-U(1)-O(1)$ & $92.7(7)$ \\
\hline $\mathrm{C}(5)-\mathrm{H}(5)$ & 0.9300 & $\mathrm{~N}(1)-\mathrm{U}(1)$ & $2.651(14)$ & $\mathrm{C}(10)-\mathrm{C}(11)-\mathrm{C}(12)$ & 120.0 & $O(7)-U(1)-O(3)$ & $88.9(8)$ \\
\hline$C(6)-C(7)$ & $1.43(2)$ & $C(2)-C(1)-C(6)$ & 120.0 & $\mathrm{C}(10)-\mathrm{C}(11)-\mathrm{H}(11)$ & 120.0 & $\begin{array}{l}O(6)-U(1)-O(3) O(6)- \\
U(1)-O(3)\end{array}$ & $90.6(7)$ \\
\hline$C(8)-O(1)$ & $1.329(19)$ & $C(2)-C(1)-O(3)$ & $116.0(11)$ & $\mathrm{C}(12)-\mathrm{C}(11)-\mathrm{H}(11)$ & 120.0 & $\mathrm{O}(1)-\mathrm{U}(1)-\mathrm{O}(3)$ & $140.7(6)$ \\
\hline$C(8)-C(9)$ & 1.3900 & $\begin{array}{l}C(6)-C(1)- \\
O(3) C(6)-C(1)- \\
O(3)\end{array}$ & $124.0(11)$ & $\mathrm{C}(13)-\mathrm{C}(12)-\mathrm{C}(11)$ & 120.0 & $\mathrm{O}(7)-\mathrm{U}(1)-\mathrm{O}(5)$ & $95.8(6)$ \\
\hline$C(8)-C(13)$ & 1.3900 & $C(3)-C(2)-C(1)$ & 120.0 & $\mathrm{C}(13)-\mathrm{C}(12)-\mathrm{H}(12)$ & 120.0 & $\mathrm{O}(6)-\mathrm{U}(1)-\mathrm{O}(5)$ & $81.0(5)$ \\
\hline$C(9)-C(10)$ & 1.3900 & $\mathrm{C}(3)-\mathrm{C}(2)-\mathrm{H}(2)$ & 120.0 & $\mathrm{C}(11)-\mathrm{C}(12)-\mathrm{H}(12)$ & 120.0 & $\mathrm{O}(1)-\mathrm{U}(1)-\mathrm{O}(5)$ & $138.6(5)$ \\
\hline $\mathrm{C}(9)-\mathrm{H}(9)$ & 0.9300 & $\mathrm{C}(1)-\mathrm{C}(2)-\mathrm{H}(2)$ & 120.0 & $\mathrm{C}(12)-\mathrm{C}(13)-\mathrm{C}(8)$ & 120.0 & $\mathrm{O}(3)-\mathrm{U}(1)-\mathrm{O}(5)$ & $80.5(5)$ \\
\hline$C(10)-C(11)$ & 1.3900 & $C(2)-C(3)-C(4)$ & 120.0 & $C(12)-C(13)-C(14)$ & $116.5(11)$ & $\mathrm{O}(7)-\mathrm{U}(1)-\mathrm{N}(1)$ & $76.7(6)$ \\
\hline $\mathrm{C}(10)-\mathrm{H}(10)$ & 0.9300 & $\mathrm{C}(2)-\mathrm{C}(3)-\mathrm{H}(3)$ & 120.0 & $\mathrm{C}(8)-\mathrm{C}(13)-\mathrm{C}(14)$ & $123.5(11)$ & $\mathrm{O}(6)-\mathrm{U}(1)-\mathrm{N}(1)$ & $102.0(6)$ \\
\hline $\mathrm{C}(11)-\mathrm{C}(12)$ & 1.3900 & $\mathrm{C}(4)-\mathrm{C}(3)-\mathrm{H}(3)$ & 120.0 & $\mathrm{C}(8)-\mathrm{O}(1)-\mathrm{U}(1)$ & $145.5(13)$ & $\mathrm{O}(1)-\mathrm{U}(1)-\mathrm{N}(1)$ & $70.6(5)$ \\
\hline $\mathrm{C}(11)-\mathrm{H}(11)$ & 0.9300 & $C(3)-C(4)-C(5)$ & 120.0 & $\mathrm{C}(1)-\mathrm{O}(3)-\mathrm{U}(1)$ & $130.6(9)$ & $\mathrm{O}(3)-\mathrm{U}(1)-\mathrm{N}(1)$ & $146.2(5)$ \\
\hline$C(12)-C(13)$ & 1.3900 & $\mathrm{C}(3)-\mathrm{C}(4)-\mathrm{H}(4)$ & 120.0 & $\mathrm{~N}(2)-\mathrm{C}(7)-\mathrm{C}(6)$ & $126.3(17)$ & $\mathrm{O}(5)-\mathrm{U}(1)-\mathrm{N}(1)$ & $70.9(4)$ \\
\hline $\mathrm{C}(12)-\mathrm{H}(12)$ & 0.9300 & $\mathrm{C}(5)-\mathrm{C}(4)-\mathrm{H}(4)$ & 120.0 & $\mathrm{~N}(2)-\mathrm{C}(7)-\mathrm{H}(7)$ & 116.9 & $\mathrm{O}(7)-\mathrm{U}(1)-\mathrm{N}(2)$ & $90.1(6)$ \\
\hline$C(13)-C(14)$ & $1.47(2)$ & $C(6)-C(5)-C(4)$ & 120.0 & $\mathrm{C}(6)-\mathrm{C}(7)-\mathrm{H}(7)$ & 116.9 & $\mathrm{O}(6)-\mathrm{U}(1)-\mathrm{N}(2)$ & $92.6(6)$ \\
\hline $\mathrm{O}(1)-\mathrm{U}(1)$ & $2.244(16)$ & $\mathrm{C}(6)-\mathrm{C}(5)-\mathrm{H}(5)$ & 120.0 & $\mathrm{~N}(1)-\mathrm{C}(14)-\mathrm{C}(13)$ & $130.0(17)$ & $\mathrm{O}(1)-\mathrm{U}(1)-\mathrm{N}(2)$ & $71.9(5)$ \\
\hline $\mathrm{O}(3)-\mathrm{U}(1)$ & $2.272(15)$ & $\mathrm{C}(4)-\mathrm{C}(5)-\mathrm{H}(5)$ & 120.0 & $\mathrm{~N}(1)-\mathrm{C}(14)-\mathrm{H}(14)$ & 115.0 & $\mathrm{O}(3)-\mathrm{U}(1)-\mathrm{N}(2)$ & $68.8(5)$ \\
\hline $\mathrm{O}(6)-\mathrm{U}(1)$ & $1.779(19)$ & $C(5)-C(6)-C(1)$ & 120.0 & $\mathrm{C}(13)-\mathrm{C}(14)-\mathrm{H}(14)$ & 115.0 & $\mathrm{O}(5)-\mathrm{U}(1)-\mathrm{N}(2)$ & $148.7(4)$ \\
\hline $\mathrm{O}(7)-\mathrm{U}(1)$ & $1.74(2)$ & $C(5)-C(6)-C(7)$ & $117.8(11)$ & $\mathrm{C}(7)-\mathrm{N}(2)-\mathrm{O}(4)$ & $111.6(15)$ & $\mathrm{N}(1)-\mathrm{U}(1)-\mathrm{N}(2)$ & $140.2(4)$ \\
\hline $\mathrm{C}(7)-\mathrm{N}(2)$ & $1.283(16)$ & $C(1)-C(6)-C(7)$ & $122.2(11)$ & $\mathrm{C}(7)-\mathrm{N}(2)-\mathrm{U}(1)$ & $123.4(11)$ & & \\
\hline
\end{tabular}


Table S9 EXAFS fitting parameters at the U L3-edge for various samples.

\begin{tabular}{|c|c|c|c|c|c|c|}
\hline Sample & Shell & $\mathrm{N}^{\mathrm{a}}$ & $\mathrm{R}(\AA)^{\mathrm{b}}$ & $\sigma^{2}\left(\AA^{2} \cdot 10^{-3}\right)^{\mathrm{c}}$ & $\begin{array}{c}\Delta \mathrm{E} 0(\mathrm{eV}) \\
\mathrm{d}\end{array}$ & $\begin{array}{c}R \text { factor } \\
(\%)\end{array}$ \\
\hline \multirow{2}{*}{ U3 } & $\mathrm{U}-\mathrm{O}$ & 2.3 & 1.77 & 1.9 & & \\
\cline { 2 - 5 } & $\mathrm{U}-\mathrm{O}$ & 4.3 & 2.41 & 12.3 & \multirow{2}{*}{10.8} & 0.3 \\
\cline { 2 - 5 } & $\mathrm{U}-\mathrm{O}$ & 1.0 & 2.60 & 8.8 & & \\
\hline
\end{tabular}

${ }^{a} N$ : coordination numbers; ${ }^{b} R$ : bond distance; ${ }^{c} \sigma^{2}$ : Debye-Waller factors; ${ }^{d} \Delta E_{0}$ : the inner potential correction. $R$ factor: goodness of fit.

\section{XAFS measurements:}

The X-ray absorption find structure spectra (Fe K-edge) were collected at 1W1B station in Beijing Synchrotron Radiation Facility (BSRF). The storage rings of BSRF was operated at $2.5 \mathrm{GeV}$ with an average current of $250 \mathrm{~mA}$. Using Si(111) doublecrystal monochromator, the data collection were carried out in transmission/fluorescence mode using ionization chamber. All spectra were collected in ambient conditions.

\section{XAFS Analysis and Results:}

The acquired EXAFS data were processed according to the standard procedures using the ATHENA module implemented in the IFEFFIT software packages. ${ }^{57-59}$ The k3-weighted EXAFS spectra were obtained by subtracting the post-edge background from the overall absorption and then normalizing with respect to the edge-jump step. Subsequently, k3-weighted $\chi(\mathrm{k})$ data of Fe K-edge were Fourier transformed to real $(\mathrm{R})$ space using a hanning windows $\left(\mathrm{dk}=1.0 \AA^{-1}\right)$ to separate the EXAFS contributions from different coordination shells. To obtain the quantitative structural parameters around central atoms, least-squares curve parameter fitting was performed using the ARTEMIS module of IFEFFIT software packages. 


\section{References}

S1. Jr., W. S. H.; Offerman, R. E. Preparation of Graphitic Oxide. J. Am. Chem. Soc. $1958,80,1339$.

S2. Georgakilas, V.; Tiwari, J. N.; Kemp, K. C.; Perman, J. A.; Bourlinos, A. B.; Kim, K. S.; Zboril, R. Noncovalent Functionalization of Graphene and Graphene Oxide for Energy Materials, Biosensing, Catalytic, and Biomedical Applications. Chem. Rev. 2016, 116, 5464-5519.

S3. Lin, K.; Chen, Q.; Gerhardt, M. R.; Tong, L.; Kim, S. B.; Eisenach, L.; Valle, A. W.; Hardee, D.; Gordon, R. G.; Aziz, M. J.; Marshak, M. P. Alkaline quinone flow battery. Science 2015, 349, 1529-1532.

S4. Orazem, M. E.; Tribollet, B. Electrochemical impedance spectrochemical methods. Wiley, Hobo-ken, NJ 2011.

S5. Zhang, H.; Zhang, Y.; Gu, C.; Ma, Y. G. Electropolymerized Conjugated Microporous Poly(zinc-porphyrin) Films as Potential Electrode Materials in Supercapacitors. Adv. Energy Mater. 2015, 5, 1402175.

S6. Yuan, K.; Xu, Y.; Uihlein, J.; Brunklaus, G.; Shi, L.; Heiderhoff, R.; Que, M.; Forster, M.; Chassé, T.; Pichler, T.; Riedl, T.; Chen, Y.; Scherf, Ullrich. Straightforward Generation of Pillared, Micorporous Graphene Frameworks for Use in Supercapacitors. Adv. Mater. 2015, 27, 6714-6721.

S7. Ravel, B.; Newville, M. ATHENA, ARTEMIS, HEPHAESTUS: data analysis for Xray absorption spectroscopy using IFEFFIT. J. Synchrotron Radiat. 2005, 12, 537-541.

S8. Koningsberger, D. C.; Prins, R. X-ray Absorption: Principles, Applications, Techniques of EXAFS, SEXAFS, and XANES (eds Koningsberger, D. C.; Prins, R.) Vol. 92 (Wiley, 1988).

S9. Rehr, J. J.; Albers, R. C. Theoretical approaches to X-ray absorption fine structure. Rev. Mod. Phys. 2000, 72, 621-654. 